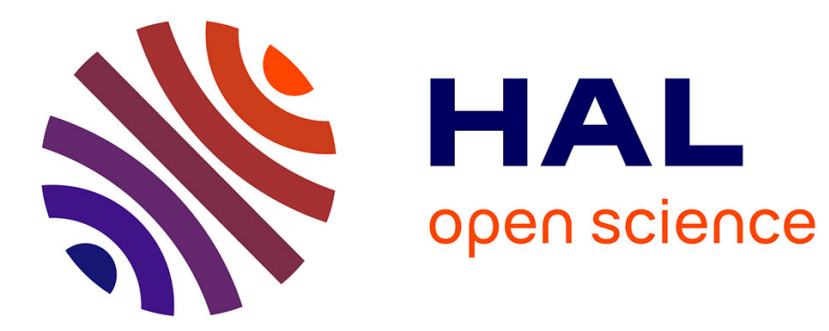

\title{
Numerical studies of frictional responses when cutting hybrid CFRP/Ti composite
}

\author{
Jinyang Xu, Mohamed El Mansori
}

\section{To cite this version:}

Jinyang Xu, Mohamed El Mansori. Numerical studies of frictional responses when cutting hybrid CFRP/Ti composite. International Journal of Advanced Manufacturing Technology, 2016, 87 (1-4), pp.657-675. 10.1007/s00170-016-8512-9 . hal-02417773

\section{HAL Id: hal-02417773 \\ https://hal.science/hal-02417773}

Submitted on 18 Dec 2019

HAL is a multi-disciplinary open access archive for the deposit and dissemination of scientific research documents, whether they are published or not. The documents may come from teaching and research institutions in France or abroad, or from public or private research centers.
L'archive ouverte pluridisciplinaire HAL, est destinée au dépôt et à la diffusion de documents scientifiques de niveau recherche, publiés ou non, émanant des établissements d'enseignement et de recherche français ou étrangers, des laboratoires publics ou privés. 


\title{
Numerical studies of frictional responses when cutting hybrid CFRP/Ti composite
}

\author{
Jinyang $\mathrm{Xu}^{1} \cdot$ Mohamed EI Mansori $^{1}$
}

\begin{abstract}
In manufacturing sectors, machining hybrid $\mathrm{CFRP} / \mathrm{Ti}$ is usually an extremely challenging task due to the disparate natures of each stacked constituent involved and their respectively poor machinability. The current research focus of hybrid CFRP/Ti cutting was primarily made via the experimental studies, which exhibited high cost and time consuming. In this paper, a new contribution was provided to study the key frictional responses dominating the bi-material machining via the numerical approach. To this aim, a multi-physical model was developed by implementing different constitutive laws and damage criteria to construct the anisotropic machinability of the stacked composite. The interrelated effects of the multi-toolwork frictional behavior on hybrid CFRP/Ti cutting were precisely investigated with respect to the specific cutting energy consumption, machined surface morphology, and affected subsurface damage. A special focus was made to clarify the cutting sequence's influences on the hybrid cutting operation. The numerical results highlighted the reasonable $\mathrm{CFRP} \rightarrow \mathrm{Ti}$ cutting sequence for hybrid composite machining and the pivotal role of multi-tool-work interaction in affecting the frictional responses induced by cutting.
\end{abstract}

Jinyang Xu

jinyang.xu@ensam.eu

1 Laboratoire Mécanique, Surfaces, Matériaux \& Procédés (MSMP - EA 7350), Arts et Métiers ParisTech,

Châlons-en-Champagne 51006, France
Keywords Hybrid composite stack · FE analysis · Anisotropic machinability $\cdot$ Specific cutting energy $\cdot$ Machined surface morphology $\cdot$ Subsurface damage

$\begin{array}{ll}\text { Nomenclature } \\ \text { CFRP } & \text { Carbon fiber reinforced polymer } \\ \text { EHM } & \text { Equivalent homogeneous material } \\ \text { FE } & \text { Finite element } \\ \text { HSC } & \text { High-speed cutting } \\ \text { OCC } & \text { Orthogonal cutting configuration } \\ a_{c} & \text { Cutting depth } \\ \text { CFRP } \rightarrow \text { Ti } & \text { Cutting-sequence strategy from CFPR } \\ & \text { phase to Ti phase } \\ D_{C F R P} & \text { Composite-phase damage extent } \\ D_{d e l} & \text { Interface delamination extent } \\ f & \text { Feed rate } \\ F_{c} & \text { Main cutting force } \\ F_{c, C F R P} & \text { Main cutting force of CFRP-phase cutting } \\ F_{c, T i} & \text { Main cutting force of Ti-phase cutting } \\ N & \text { Number of sampling nodes } \\ R_{a} & \text { One-dimensional arithmetic mean } \\ & \text { roughness parameter } \\ r_{\varepsilon} & \text { Tool edge radius } \\ \text { Ti } \rightarrow \text { CFRP } & \text { Cutting-sequence strategy from } \\ & \text { Ti phase to CFRP phase } \\ u & \text { Specific cutting energy } \\ \bar{u} & \text { Equivalent specific cutting energy } \\ v_{c} & \text { Cutting speed } \\ w & \text { Cutting width } \\ \alpha & \text { Tool rake angle }\end{array}$




$\begin{array}{ll}\gamma & \text { Tool clearance angle } \\ \theta & \text { Fiber orientation } \\ \mu & \text { Friction coefficient of the multi-tool-work } \\ & \text { interaction }\end{array}$

\section{Introduction}

In modern aerospace industry, the hybrid composite stack has been used across a broad range of applications in various aspects of manufacturing community to meet the dual demands of lightweight and structural properties of aircrafts [1-3]. The multi-phase material made up of carbon-fiberreinforced polymer (CFRP) and titanium alloy (Ti) is a typical example of hybrid composite configuration. The key advantages of delivering energy saving and improving system performance have awarded the material a promising alternative to replacing conventional standard composite applications and single metal alloy applications in various industrial production [4-7]. The hybrid CFRP/Ti composite usually provides enhanced material properties so that the attractive aspects of each stacked constituent are utilized while their weaknesses are avoided [8]. Many giant aircraft manufacturers including Boeing, Airbus, Bombardier, etc., have actively employed such "composite-to-metal" alliance in advanced airplanes to enhance the characteristics of new-generation structures favoring the energy saving. One of the typical applications is the use of the wing-fuselage connections in the newgeneration Boeing 787 Dreamliner [4].

Despite its widespread applications, mechanical machining of such "composite-to-metal" alliance still represents the most challenging task in modern manufacturing sectors due to the disparate properties of each stacked constituent involved and their respectively poor machinability. For instance, the CFRP laminate shows anisotropic behavior, abrasive nature, and low thermal conductivity, which leads to poor machined surface quality and excessive tool wear in machining [9, 10]. For Ti alloy, it exhibits low thermal conductivity and strong chemical affinity to most tool materials [11], which usually results in high force/heat generation and serious tool wear [12-14] predominating the machining operation. Fundamentally, the reason can be thoroughly tracked back to the multi-toolwork interaction governing the CFRP/Ti machining. The non-compliance between the tool-composite interaction, on one hand, and the tool-metal interaction, on another hand, induces local interface discontinuities and, hence, affects the cutting behavior. These discontinuities present the major obstacles to be overcome for $(i)$ better controlling of cutting conditions and (ii) proper selection of the tool-work configuration [4].

Moreover, the multi-tool-work interaction also acts as the key root of various mechanical/physical phenomena induced in the CFRP/Ti chip removal process. Specifically, the multi- tool-work interaction dominating the CFRP/Ti cutting can be decomposed in two fundamental couplings, $(i)$ the tool-chip coupling including the tool-Ti/chip and tool-CFRP/chip interactions $\rightarrow$ controlling the overall chip-separation mode of the bi-material system and (ii) the tool-work coupling comprising the tool-Ti/work and tool-CFRP/work interactions $\rightarrow$ predominating the induced subsurface damage and the machined part quality. The key characteristic directly ruled the multi-tool-work interaction behavior is the friction coefficient $(\mu)$. To minimize the severe frictional consumption, and hence to improve the machinability of the hybrid composite stack, various experimental researches have been dedicated to the use of superior cutting tools, optimal cutting parameters, and favorable cutting environments. For instance, Ramulu et al. [5] studied the machinability of composite ( $\mathrm{Gr} / \mathrm{Bi}) /$ titanium stacks by using different cutting tool materials including high-speed steel (HSS), high-speed cobalt (HSS-Co), and carbide material. Severe composite matrix degradation, Ti burr formation, and rapid tool wear were detected, regardless of the used tool materials. The carbide tool was found to improve greatly the tribological behavior of the multi-tool-work interaction and hence led to the minimal surface imperfection and maximum tool life. Besides, Park et al. [6, 7] investigated the tool wear mechanisms of hybrid CFRP/Ti6Al4V machining by using tungsten carbide (WC) tool and polycrystalline diamond (PCD) tool. The experimental results showed that the PCD tool suffered less Ti chip adhesion and exhibited higher wear resistance than the WC tool due to its significant improvement of the multi-tool-work interaction controlling the hybrid composite machining. Additionally, some scholars [15-18] argued that the use of special geometrical tools, e.g., higher point angle drill, K-land deign drill, etc., could also ameliorate the multi-tool-work frictional behavior of the hybrid composite cutting and thus lead to the improvement of the machined surface quality. With respect to the cutting parameters and cutting environment, several scholars [19-21] pointed out that the use of optimal cutting parameters (cutting speed $\left(v_{c}\right)$ and feed rate $\left.(f)\right)$ or reasonable cutting environments should be another feasible solution to reforming the friction behavior of the multi-tool-work interaction and hence improve the machinability of the stacked material.

In sum, the previous studies [5-7, 15-21] have provided a better comprehension of the cutting physics governing the hybrid CFRP/Ti machining. However, several methodological shortages and cutting mysteries still proceed in the relevant research field. For instance, on one hand, these mentioned investigations were performed solely via the experimental method, which exhibited time-consuming and high cost because of the exhausting and expensive trials demanded. In contrast, the numerical method, to some extent, could offer sufficient capabilities to overcome the several technical limitations arising from experimentation. On another hand, most of the scholars ignored to inspect the influences of different 
cutting-sequence strategies (i.e., cutting from $\mathrm{CFRP} \rightarrow \mathrm{Ti}$ or $\mathrm{Ti} \rightarrow \mathrm{CFRP}$ ) on the hybrid machining process. The key differences between the two mentioned cutting-sequence strategies and also their effects on hybrid CFRP/Ti machining were still not well studied.

With respect to the investigations on single composite and single titanium cutting modeling, a large amount of work has been performed in the past few decades. For instance, Arola and Ramulu [22] adopted a macro-mechanical model (considering the composite as an equivalent homogeneous material (EHM)) for simulating the chip formation when cutting glass/ epoxy composite. A 2D quasi-static plane stress analysis incorporating both the maximum stress and the Tsai-Hill failure criteria was utilized. The model was reported to capture accurately the estimations of cutting force as compared to the experimental results. Ramesh et al. [23] analyzed the stress distribution and chip failure modes governing the FRPs machining by using an anisotropic plastic theory. The maximum stress levels were found to occur near the tool nose for $0^{\circ}$ fiber orientation, while for other fiber orientations, the maximum stresses were identified below the tool nose. In addition, Mahdi and Zhang [24] established a quasi-static 2D macromechanical model by using the Tsai-Hill criteria for orthogonal cutting modeling of fiber reinforced composite. The variation of cutting force versus fiber orientation was precisely studied. The Tsai-Hill criteria were found to yield reasonable cutting predictions compared with the experimental measurements. Besides, some other researches dealing with cutting modeling of single composite laminate can also be found in the open literature [25-27]. For Ti alloy cutting modeling, the Johnson-Cook (JC) constitutive model was widely used for chip separation estimation, force or damage prediction, etc. For example, Xi et al. [28] adopted the JC constitutive model based on the updated Lagrangian formulation to simulate the machining operations of thermally turning of Ti6Al4V. The element deletion algorithm based on equivalent plastic displacement was implemented to promote the chip separation. The predicted chip morphology showed a strong correlation with the experimental observation. Chen et al. [29] used the JC constitutive model with an energy-based ductile fracture criterion for modeling the high-speed cutting of Ti6Al4V alloy. The simulated results in terms of cutting force and chip morphology yielded good agreements with the experimental findings.

However, for numerical studies on hybrid CFRP/Ti cutting modeling, still very limited researches $[8,30,31]$ can be found in the open literature. Previously, our preliminary numerical work $[8,30,31]$ had made an attempt to clarify the chip separation process, force generation, and induced subsurface damage formation dominating the hybrid CFRP/Ti machining. And it was found that the mechanical/physical response transition from CFRP cutting to Ti cutting or vice versa usually resulted in severe delamination damage focused on the bi- material interface. The interface delamination was characterized by a "V-shape" like notch, which was greatly influenced by the input variables (cutting speed, feed rate, and fiber orientation). However, the influences of the key activated factor, i.e., the multi-tool-work interaction, on affecting the hybrid CFRP/Ti machining were still not investigated. As discussed earlier, the multi-tool-work interaction, in reality, acts as the key root of various frictional responses promoted in the bimaterial machining. Clarifying the frictional responses versus the multi-tool-work interaction should do some help to improve the machinability of the stacked composite.

On this basis, this article was thus dedicated to bringing more physical comprehension of the CFRP/Ti machining with special focuses on the frictional responses by considering also the different cutting-sequence strategies (CFRP $\rightarrow \mathrm{Ti}$ and $\mathrm{Ti} \rightarrow \mathrm{CFRP}$ ). To this aim, a multi-physical model was developed to simulate the anisotropic machinability of the heterogeneous CFRP/Ti material. To study the fundamental frictional responses governing the bi-material cutting, the main structure of the paper aims to alter the behavior of the tool-material interface via the friction coefficient $(\mu)$ and then to clarify its influence on various induced cutting responses.

\section{Numerical setup of the OC model}

In the present contribution, a 2D FE model was developed to simulate the hybrid composite cutting process based on the assumption of orthogonal cutting configuration (OCC). Despite the simplifications of some details of the multi-toolwork interactions involved in the actual production, the OCC still takes into account the elementary features of the real cutting and the most essential variables for numerical simulation. Moreover, the orthogonal cutting modeling also represents the most convenient way to study the fundamental cutting physics governing the various actual manufacturing operations with low computation cost and high simulation efficiency.

\subsection{Geometrical details of the multi-tool-work interaction and boundary conditions}

The FEA software Abaqus ${ }^{\mathrm{TM}}$, a Lagrangian explicit code, was employed to simulate the CFRP/Ti cutting process. Figure 1 shows the basic geometries and dimensions of the FE models. Two setups of $\mathrm{OC}$ models on different cutting sequences, i.e., (i) $\mathrm{Ti} \rightarrow \mathrm{CFRP}$ and (ii) $\mathrm{CFRP} \rightarrow \mathrm{Ti}$, were established to reveal their influences on the hybrid cutting operation. Each OC model incorporated four basic physical constituents, i.e., the tool part, Ti part, interface, and CFRP part with a total dimension of $2 \mathrm{~mm} \times 1 \mathrm{~mm}(L \times H)$ for the workpiece, as shown schematically in Fig. 1. 
Fig. 1 Schematic illustration of the established OC models for hybrid CFRP/Ti machining $\left(\alpha=0^{\circ}\right.$ and $\left.\gamma=7^{\circ}\right)$. a Ti $\rightarrow$ CFRP cutting sequence. $\mathbf{b} \mathrm{CFRP} \rightarrow \mathrm{Ti}$ cutting sequence $((1,2)$ represents the material coordinate system where $1 \rightarrow$ fiber direction, $2 \rightarrow$ transverse direction, $F_{c}$ indicates the cutting force and $F_{t}$ signifies the thrust force)
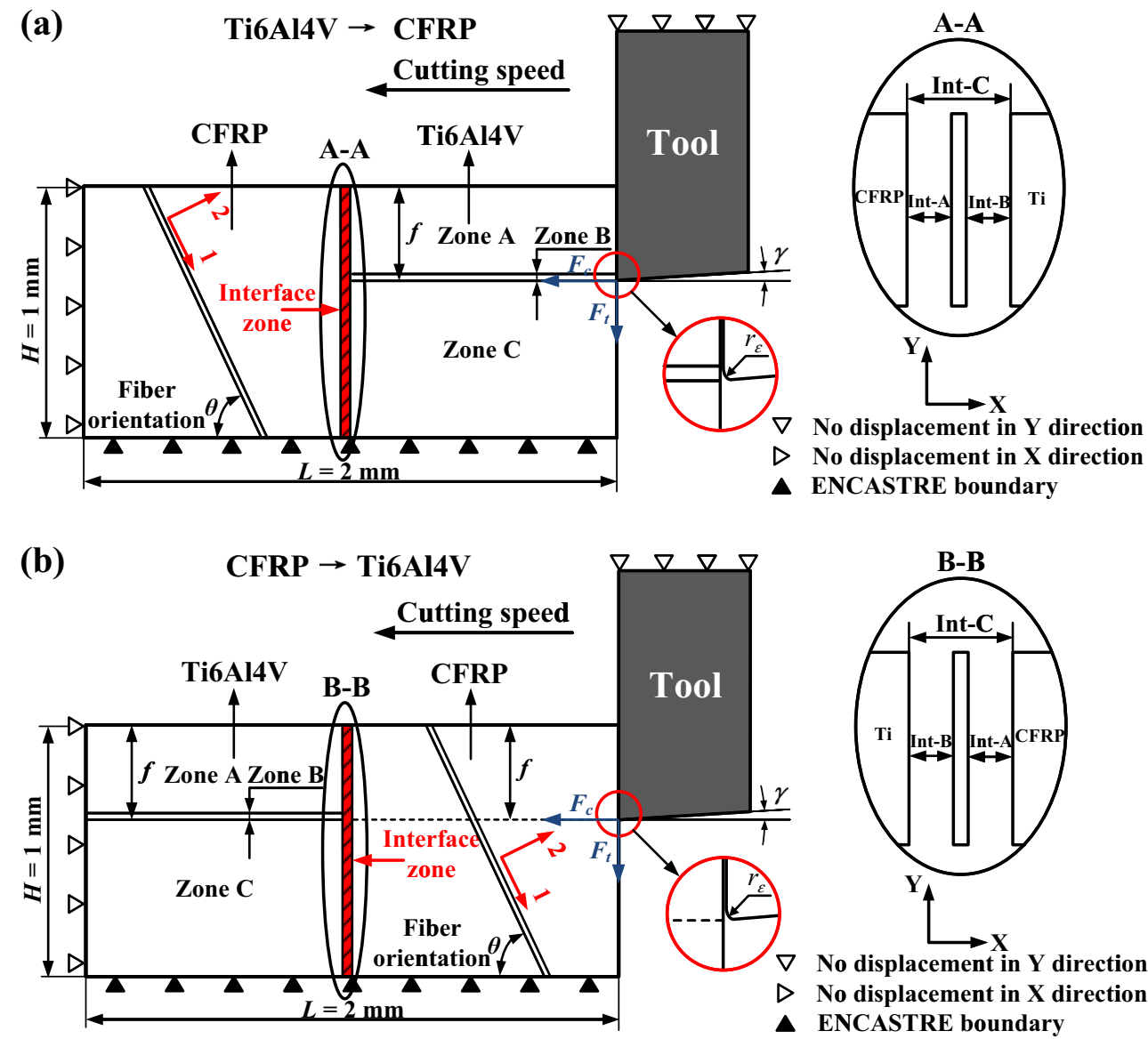

For the tool-workpiece geometries and boundary conditions (as presented in Fig. 1), sufficient cutting length of probably $1 \mathrm{~mm}$ was used for both the CFRP phase and $\mathrm{Ti}$ phase to attain the steady cutting conditions. Displacements of the workpiece bottom were fixed in all directions while the left edge of the stack model was constrained to move in the cutting speed direction (X direction). The cutting tool was simulated as a rigid body, i.e., no deformation during cutting, which is usually a widely used standard simplification of the tool model establishment in Abaqus software. Since the tool part was assumed as a fully rigid material, for Abaqus simulation, it requires no definition of the material property in FEA. Therefore, the tool material was not provided in the study. A cutting velocity was imposed on its reference node through the negative $\mathrm{X}$ direction to complete the cutting simulation. The tool was configured by defined geometries of rake and clearance angles $\left(\alpha=0^{\circ}\right.$ and $\left.\gamma=7^{\circ}\right)$ and tool edge radius $\left(r_{\varepsilon}=2 \mu \mathrm{m}\right)$ as depicted in Fig. 1. The center of the tool nose was placed exactly at the feedrate distance from the upper surface.

For Ti phase, the four-node plane-strain thermally coupled quadrilateral element type CPE4RT which has better convergence properties was used for the whole set of the Ti elements. To optimize the contact management during the simulation, the entire Ti phase was divided into three physical zones with different mesh generations. As shown in Fig. 1, zone A represents the separated Ti chip layer, zone $\mathrm{B}$ denotes the predefined separation path, and zone $\mathrm{C}$ indicates the machined Ti surface. Zones $\mathrm{A}$ and $\mathrm{B}$ were defined by very fine mesh density since they were close to the region of the multi-tool-work interaction. In contrast, zone $\mathrm{C}$ was mashed coarsely as it was far away from the zone of interest. For zones A and B, a higher density mesh with approximately $10-\mu \mathrm{m}$ element edge length was defined, which was much smaller than the chip thickness, and thus could provide sufficient elements for modeling of the complete Ti chip formation. For zone $\mathrm{C}$ of the Ti layer, the used mesh density was not uniform as the density on connecting zone B was higher than the rest. And the element edge length of zone $\mathrm{C}$ increased from $10 \mu \mathrm{m}$ on the top edge linking to the predefined separation path (zone B) to $78 \mu \mathrm{m}$ on the fixed bottom edge.

For CFRP phase, the composite in reality consists of two distinct phases (reinforcing fiber and polymer matrix) and globally exhibits anisotropic properties [9]. However, 
for simulations in a macro-mechanical model, the fiber reinforced laminate is commonly assumed as an equivalent homogeneous material (EHM) by most numerical study cases $[27,30,32,33]$. In the present model, the EHM assumption was adopted. The CFRP phase was modeled by using four-node plane-stress linearly interpolated elements (CPS4R) with reduced integration and automatic hourglass control. Note that a plane-strain analysis that is used typically for metal cutting was not appropriate for cutting modeling of CFRP laminates due to the extent of out of plane material displacement observed while cutting experiments [34-36]. To achieve the balance between the simulation accuracy and time efficiency, the mesh density was set uniformly for all the composite phase with approximately $5-\mu \mathrm{m}$ element edge length by referring to some relevant research work $[32,33]$. The interaction between the CFRP phase and the cutting tool was ruled by using the algorithm surface-node-surface contact.

The interface layer connecting the Ti phase and CFRP phase was simulated as a quick transition zone by using cohesive elements available in the Abaqus/ Explicit code. Note that the use of interface layer here aims to serve as a technical control for the "CFRP-toTi" contact management. A triangular traction-separation cohesive formulation with linear softening was adopted to represent its mechanical responses. The assembly of the interface, Ti phase, and CFRP phase was carried out by setting a constraint type joining (tie constraint). Besides, two contact pairs (Int-A and Int-B) with the specification of penalty contact algorithm and rough friction formulation were established among the interface, CFRP phase, and Ti phase as shown in Fig. 1, which made the interface zone as a slave surface. Besides, an additional contact pair referring to the Int$\mathrm{C}$ (as shown in Fig. 1) was also assigned between the CFRP layer and $\mathrm{Ti}$ layer in order to avoid them to penetrate into each other when the interface elements were eroded.

Moreover, with respect to the frictional behavior of the multi-tool-work interaction, it plays a pivotal role in affecting the various physical phenomena activated at the hybrid composite machining and thus determines the surface integrity of the machined part. However, the friction characteristic dominating the tool-chip/work interface is difficult to determine since it is influenced by many factors such as cutting speed, contact pressure, and temperature. Extensive studies have been performed on this issue, and several models have revealed that there exist two distinct regions of sticking and sliding predominating the tool-chip/work interface. In the current simulation, the most-used Zorev's model [37], which considered the mentioned two distinct friction regions, was adopted. This model, also termed as an extended Coulomb friction model, was used here to simulate the multi-tool-work interaction and was given as follows.

$\left\{\begin{array}{l}\text { Sticking region }: \tau=\bar{\tau}_{\max } ; \text { when } \tau \geq \bar{\tau}_{\max } \\ \text { Sliding region: } \tau_{\text {crit }}=\mu \sigma ; \text { when } \tau<\bar{\tau}_{\max }\end{array}\right.$

where $\tau_{\text {crit }}$ is defined as the critical shear stress, at which sliding of the surfaces starts as a fraction of the contact pressure $(\sigma)$ between the surfaces $\left(\tau_{\text {crit }}=\mu \sigma\right)$. An upper bound estimate for $\bar{\tau}_{\max }$ is $\sigma_{y} / \sqrt{3}$, which $\sigma_{y}$ is the Mises yield stress of the material adjacent to the surface.

During the numerical simulation, the friction coefficient of multi-tool-work interaction $(\mu)$ was considered as an input variable for numerical computation. Different $\mu$ values were implemented to inspect the frictional responses of hybrid CFRP/Ti machining.

\subsection{Material behavior and progressive damage criterion}

The simulated hybrid CFRP/Ti stack was composed of unidirectional (UD) T300/914 carbon/epoxy laminate and Ti6Al4V alloy. The basic mechanical/physical properties of the hybrid CFRP/Ti stack are summarized in Table 1 [28, 38-42]. Detailed material behaviors and implemented damage criteria for each physical constituent are illustrated in the following subsections.

\subsubsection{Ti-phase constitutive model}

To simulate the chip separation of the Ti phase, the most-used Johnson-Cook (JC) constitutive model and JC damage law [43, 44] were utilized to describe its ductile failure behavior. The JC constitutive model expresses the physical behavior of the Ti phase in terms of equivalent flow stress and equivalent plastic strain by considering large strain, high strain rate, and temperature dependent visco-plasticity. In addition, the JC constitutive model also takes into account the strain hardening effect, strain rate sensitivity, and thermal softening behavior when the metal phase is operated under high strain/stress/temperature coupled machining condition. And in each time increment, the equivalent flow stress of each integration point will be calculated and evaluated. The basic expression of the JC constitutive model is shown as follows.

$$
\bar{\sigma}=\underbrace{\left(A+B \bar{\varepsilon}^{n}\right)}_{\text {Strain hardening }} \underbrace{\left.1+C \ln \frac{\dot{\bar{\varepsilon}}}{\dot{\bar{\varepsilon}}}\right)}_{\text {Strain rate sensitivity }} \underbrace{\left[1-\left(\frac{T-T_{r}}{T_{m}-T_{r}}\right)^{m}\right]}_{\text {Thermal softening behavior }}
$$

where $\bar{\sigma}$ denotes the equivalent flow stress, $\bar{\varepsilon}$ is the 
Table 1 Material properties of the simulated CFRP/Ti stack [28, 38-42]

Workpiece material

\begin{tabular}{|c|c|c|c|c|c|}
\hline \multicolumn{2}{|l|}{ Ti6Al4V alloy [28] } & \multicolumn{2}{|l|}{ T300/914 CFRP laminate $[38,39]$} & \multicolumn{2}{|c|}{ Interface $[40-42]$} \\
\hline Density $(\rho)$ & $4430 \mathrm{~kg} / \mathrm{m}^{3}$ & Longitudinal modulus $\left(E_{1}\right)$ & $136.6 \mathrm{GPa}$ & $v$ & 0.33 \\
\hline Young's modulus $(E)$ & $113 \mathrm{GPa}$ & Transverse modulus $\left(E_{2}\right)$ & $9.6 \mathrm{GPa}$ & $K_{n n}$ & $2.0 \mathrm{GPa}$ \\
\hline Poisson's ratio $(v)$ & 0.342 & In-plane shear modulus $\left(G_{12}\right)$ & $5.2 \mathrm{GPa}$ & $K_{s s}=K_{t t}$ & $1.5 \mathrm{GPa}$ \\
\hline Thermal expansion coefficient $\left(\alpha_{T}\right)$ & $9.1 \times 10^{-6}{ }^{\circ} \mathrm{C}^{-1}$ & Major Poisson's ratio $\left(v_{12}\right)$ & 0.29 & $t_{n}^{f}$ & $60 \mathrm{MPa}$ \\
\hline Melting temperature $\left(T_{m}\right)$ & $1680^{\circ} \mathrm{C}$ & Longitudinal tensile strength $\left(X_{T}\right)$ & $1500 \mathrm{MPa}$ & $t_{s}^{f}=t_{t}^{f}$ & $80 \mathrm{MPa}$ \\
\hline Room temperature $\left(T_{r}\right)$ & $25^{\circ} \mathrm{C}$ & Longitudinal compressive strength $\left(X_{C}\right)$ & $900 \mathrm{MPa}$ & $G_{n}^{C}$ & $0.78 \mathrm{~N} / \mathrm{mm}$ \\
\hline Thermal conductivity $(\lambda)$ & $7.0 \mathrm{~W} /\left(\mathrm{m} \cdot{ }^{\circ} \mathrm{C}\right)$ & Transverse tensile strength $\left(Y_{T}\right)$ & $27 \mathrm{MPa}$ & $G_{s}^{C}=G_{t}^{C}$ & $1.36 \mathrm{~N} / \mathrm{mm}$ \\
\hline \multirow[t]{3}{*}{ Specific heat $\left(c_{p}\right)$} & $546 \mathrm{~J} /\left(\mathrm{kg} \cdot{ }^{\circ} \mathrm{C}\right)$ & $\begin{array}{l}\text { Transverse compressive strength }\left(Y_{C}\right) \\
\text { In-plane shear strength }\left(S_{12}\right)\end{array}$ & $\begin{array}{l}200 \mathrm{MPa} \\
80 \mathrm{MPa}\end{array}$ & - & \\
\hline & & Longitudinal shear strength $\left(S_{L}\right)$ & $80 \mathrm{MPa}$ & & \\
\hline & & Transverse shear strength $\left(S_{T}\right)$ & $60 \mathrm{MPa}$ & & \\
\hline
\end{tabular}

equivalent plastic strain, $\dot{\bar{\varepsilon}}$ is the equivalent plastic strain rate, $\dot{\varepsilon}_{0}$ is the reference equivalent plastic strain rate, $T$ is the workpiece temperature, $T_{m}$ is the material melting temperature, and $T_{r}$ is the room temperature. $A, B, C, m$, and $n$ are material constants, which are usually determined by fitting the strain-stress curves obtained by the split-Hopkinson bar.

The JC damage law is then expressed as follows.

$\left.\bar{\varepsilon}_{i}=\left[D_{1}+D_{2} \exp \left(D_{3} \frac{P}{\bar{\sigma}}\right)\right] 1+D_{4} \ln \frac{\dot{\bar{\varepsilon}}}{\dot{\bar{\varepsilon}}_{0}}\right)\left[1+D_{5}\left(\frac{T-T_{r}}{T_{m}-T_{r}}\right)\right]$

$\omega=\sum \frac{\Delta \bar{\varepsilon}}{\bar{\varepsilon}_{i}}$

in which, $\bar{\varepsilon}_{i}$ is the equivalent plastic strain at damage initiation, $P$ is hydrostatic pressure, $P / \bar{\sigma}$ is the stress triaxiality, $D_{1}-D_{5}$ are JC damage parameters, $\omega$ is the scalar damage parameter, and $\Delta \bar{\varepsilon}$ is the equivalent plastic strain increment. The input JC parameters are summarized in Table $2[28,45]$.

Under a given time increment, the equivalent plastic strain at each integration point of the Ti phase was computed. Once the scalar damage parameter $(\omega)$ reached 1, damage initiation was promoted, and then effective plastic displacement at

Table 2 Input parameters for JC constitutive model and JC damage law $[28,45]$

\begin{tabular}{llllll}
\hline JC constitutive model & $A(\mathrm{MPa})$ & $B(\mathrm{MPa})$ & $C$ & $n$ & $m$ \\
& 1098 & 1092 & 0.014 & 0.93 & 1.1 \\
& & & & & \\
JC damage law & $D_{1}$ & $D_{2}$ & $D_{3}$ & $D_{4}$ & $D_{5}$ \\
& -0.09 & 0.25 & -0.5 & 0.014 & 3.87 \\
\hline
\end{tabular}

failure was used to finalize the damage evolution process until the complete chip separation.

\subsubsection{CFRP-phase constitutive model}

The CFRP laminate was modeled as an EHM by also considering its anisotropic behavior relative to the fiber orientation $(\theta)$. The definition of the composite fiber orientation $(\theta)$ was made based on the introduction of the material coordinate system (1, 2) into the CFRP phase as shown schematically in Fig. 1.

The cutting behavior of the CFRP laminate has been confirmed by previous experimental studies [46-48] to be dominated by brittle-fracture mechanisms of the fiber/matrix system following four types of failure modes (fiber/matrix tensile/compression failure). A "discontinuous" shape of chips is always noted with respect to different cutting conditions in the material machining. The Hashin damage criteria considering the mentioned four types of failure were thereby adopted to replicate the machining behavior of the CFRP phase. The basic expressions of the Hashin damage criteria are illustrated in Table $3[49,50]$, where $\sigma_{11}$ and $\sigma_{22}$ are the stresses in the fiber direction and transverse direction, respectively. $\sigma_{12}$ is the in-plane shear stress.

The element erosion of the CFRP phase was conducted through the concept of stiffness degradation [32, 33]. When one type of the mentioned failure occurs, the relevant material properties $\left(E_{1}, E_{2}, G_{12}, v_{12}\right)$ will be degraded automatically as shown in Table 3 . Note that the stresses involved in the equations given by Table 3 are written in the principal material coordinate system. In the present analysis, the material property degradation depends on four associated defined variables, as listed below: $(i)$ the first variable noted HSNFTCRT represents the fiber-tensile failure mode, $(i i)$ the second HSNFCCRT represents the fiber-compression failure mode, (iii) the third HSNMTCRT represents the matrix-tensile 
Table 3 Hashin damage criteria and associated degradation rules [49, 50]

\begin{tabular}{|c|c|c|c|}
\hline Failure criteria & Failure mode & Associated defined variable & Reduced material properties \\
\hline Fiber-tensile failure $\left(\sigma_{11} \geq 0\right)$ & $D_{f t}^{2}=\left(\frac{\sigma_{11}}{X_{T}}\right)^{2}+\left(\frac{\sigma_{12}}{S_{L}}\right)^{2}$ & HSNFTCRT & $E_{1}, E_{2}, G_{12}, v_{12} \rightarrow 0$ \\
\hline Fiber-compression failure $\left(\sigma_{11}<0\right)$ & $D_{f c}^{2}=\left(\frac{\sigma_{11}}{X_{C}}\right)^{2}$ & HSNFCCRT & $E_{1}, E_{2}, G_{12}, v_{12} \rightarrow 0$ \\
\hline Matrix-tensile failure ()$\left(\sigma_{22} \geq 0\right)$ & $D_{m t}^{2}=\left(\frac{\sigma_{22}}{Y_{T}}\right)^{2}+\left(\frac{\sigma_{12}}{S_{L}}\right)^{2}$ & HSNMTCRT & $E_{2}, G_{12} \rightarrow 0$ \\
\hline Matrix-compression failure $\left(\sigma_{22}<0\right)$ & $D_{m c}^{2}=\left(\frac{\sigma_{22}}{2 S_{T}}\right)^{2}+\left[\left(\frac{Y_{C}}{2 S_{T}}\right)^{2}-1\right] \frac{\sigma_{22}}{Y_{C}}+\left(\frac{\sigma_{12}}{S_{L}}\right)^{2}$ & HSNMCCRT & $E_{2}, G_{12} \rightarrow 0$ \\
\hline
\end{tabular}

failure made, and (iv) the fourth HSNMCCRT represents the matrix-compression failure mode.

During the FE computation, the material properties at each integration point were computed for each given load. The failure modes were then evaluated and if any failure criterion reached the unity, the relevant material properties would be automatically reduced to zero according to the implemented stiffness degradation scheme. The degradation of both longitudinal and shear moduli was ruled by the fiber failure modes while the degradation of transverse and shear moduli was governed by the matrix failure modes. The procedure was repeated several times until the occurrence of the complete CFRP chip separation.

\subsubsection{Interface constitutive model}

The interface model used here aims to replicate the delamination damage occurred at the CFRP/Ti contact boundary, which was modeled by using cohesive interaction with a very small thickness (probably $5 \mu \mathrm{m}$ ). Note that the use of small interface thickness aims to minimize its influence on some other machining responses, e.g., Ti/CFRP chip separation process, cutting force generation, etc. The surface-based traction-separation law with linear softening was adopted to reproduce the mechanical responses of the cohesive interaction. The failure initiation law required to motivate the damage among the interface layer is based on the quadratic stress criterion [51, $52]$ as illustrated in the following equation.

$$
\left(\frac{\sigma_{33}}{t_{n}^{f}}\right)^{2}+\left(\frac{\sigma_{13}}{t_{s}^{f}}\right)^{2}+\left(\frac{\sigma_{23}}{t_{t}^{f}}\right)^{2}=1
$$

in which, $\sigma_{33}, \sigma_{13}$, and $\sigma_{23}$ represent the normal traction stress, shear traction stresses in two directions, respectively; $t_{n}, t_{s}$, and $t_{t}^{f}$ signify the peak normal failure strength and peak shear failure strengths in two directions, respectively.
When the damage onset was initiated, the BenzeggaghKenane (BK) damage criteria [53] and potential law [54] were used to simulate damage evolution dominating the cohesive interaction, as presented in Eqs. (6) and (7).

$$
\begin{gathered}
G_{n}^{C}+\left(G_{s}^{C}-G_{n}^{C}\right)\left(\frac{G_{s}+G_{t}}{G_{n}+G_{s}+G_{t}}\right)^{\eta}=G^{C} \\
\left(\frac{G_{n}}{G_{n}^{C}}\right)^{\beta}+\left(\frac{G_{s}}{G_{s}^{C}}\right)^{\beta}+\left(\frac{G_{t}}{G_{t}^{C}}\right)^{\beta}=1
\end{gathered}
$$

in which $G_{n}, G_{s}$, and $G_{t}$ are the released rate energies in the normal and two shear directions respectively; $G_{n}^{C}, G^{C}{ }_{s}$, and $G^{C}{ }_{t}$ are the critical values of released rate energies, $\eta$ and $\beta$ are the parameters of the laws.

Moreover, the traction-separation law controlling the interface behavior is specified by means of the stiffnesses in the normal and in the two shear directions $\left(K_{n n}, K_{s s}\right.$, and $\left.K_{t t}\right)$, the interface resistance in each direction $\left(t_{n}^{f}, t_{s}^{f}\right.$ and $\left.t_{t}\right)$, and the damage evolution through the critical released rate energy $\left(G_{n}^{C}, G_{s}^{C}\right.$, and $\left.G_{t}^{C}\right)$. The input parameters for the interface zone were adopted rigorously based on the comprehensive selection of relevant research work [40-42], as summarized in Table 1.

\section{Validation of the CFRP/Ti model}

The validation work of the CFRP/Ti model was conducted based on each phase verification since nearly no experimental work was available on orthogonal cutting of hybrid CFRP/Ti composite in the literature. As the interface was simulated as a quick transition zone by defining very small thickness (nearly $5 \mu \mathrm{m}$ ), its influence on some other machining responses (e.g., CFRP/Ti force generation, chip separation process, etc.) could be ignored. Therefore, the validation work was focused on the Ti phase verification and CFRP phase verification by referring to the open literature. For validation purpose, all the cutting 
(a)

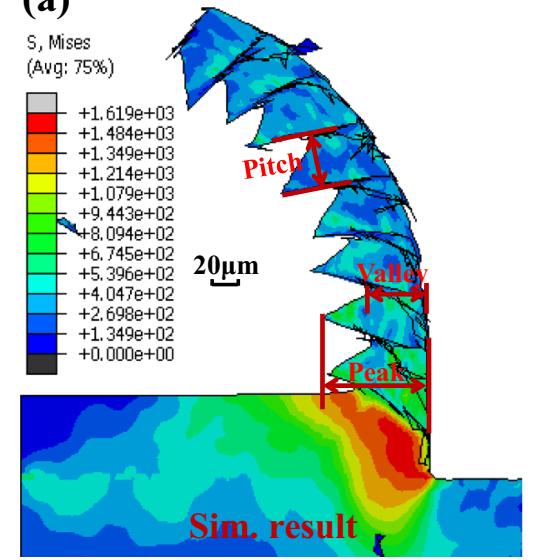

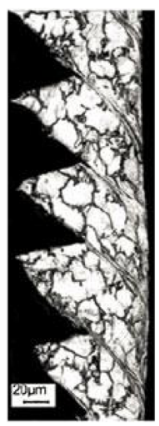

Exp. result (b)

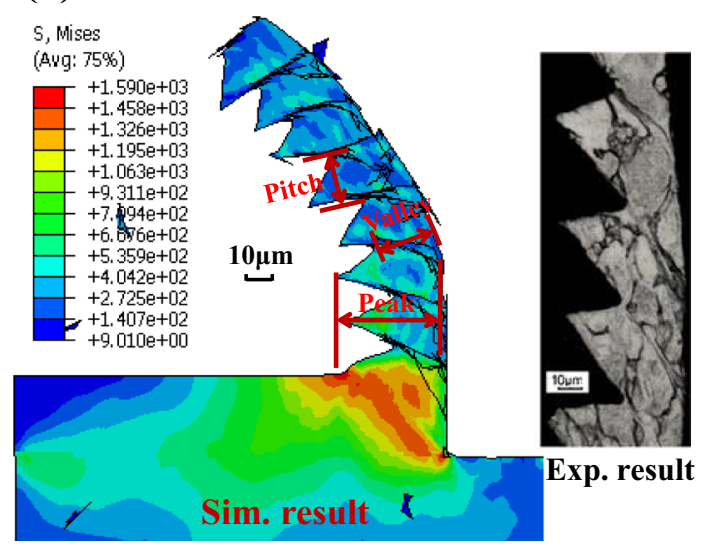

Fig. 2 Comparison of the simulated (Sim.) and experimental (Exp.) chip morphologies [55] in Ti-phase cutting modeling. a Test condition 1 $\left(v_{c}=1200 \mathrm{~m} / \mathrm{min}\right.$ and $\left.f=70 \mu \mathrm{m} / \mathrm{rev}\right)$. b Test condition $2\left(v_{c}=4800 \mathrm{~m} / \mathrm{min}\right.$ and $\left.f=35 \mu \mathrm{m} / \mathrm{rev}\right)$

conditions were used as the same in literature. Both the Tiphase model and CFRP-phase model were validated rigorously until they were capable of producing the consistent results agreed with the experimental studies from the open literature.

For Ti phase model, the validation work was performed in terms of comparison of chip morphology and cutting-force generation by referring to the experimental work done by Gentel and Hoffmeister [55]. Figure 2 shows the comparison of both simulated and experimental chip morphologies under different cutting conditions [8]. It could be seen that the simulated chip morphologies yielded a consistent agreement with the experimental observation. Moreover, the comparison between the predicted and experimental cutting force [55] (as shown in Fig. 3) also achieved good agreement with each other, which confirmed the sufficient credibility of the established Ti-phase cutting model.

For CFRP phase model, it was validated in the simplest manner of force generation versus fiber orientation $(\theta)$ as

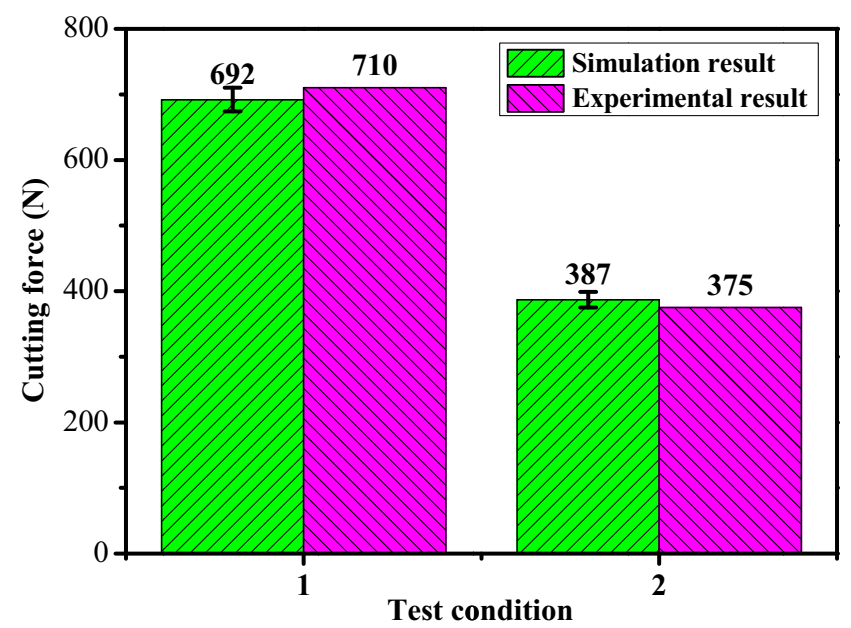

Fig. 3 Comparison of the simulated and experimental cutting forces [55] in Ti-phase cutting modeling: $\left(1: v_{c}=1200 \mathrm{~m} / \mathrm{min}\right.$ and $f=70 \mu \mathrm{m} / \mathrm{rev} ; 2$ : $v_{c}=4800 \mathrm{~m} / \mathrm{min}$ and $f=35 \mu \mathrm{m} / \mathrm{rev}$, workpiece thickness $=5 \mathrm{~mm}$ ) depicted in Fig. 4, which was the commonly used criterion for validation of composite cutting modeling. Note that in Fig. 4, the force magnitudes (in $\mathrm{N} / \mathrm{mm}$ ) were normalized as the ratio between the average level of force generation to the workpiece thickness. It can be seen that the predicted force magnitudes yielded both strong correlation with the experimental results gained by Iliescu et al. [39], which confirmed the credibility of the developed CFRP-phase cutting model. After the experimental validation, each constitutive model was assembled to perform the hybrid CFRP/Ti cutting modeling.

\section{Numerical results and discussion}

To precisely inspect the parametric effects on the hybrid cutting operation, a wide range of input cutting variables was examined for the CFRP/Ti cutting modeling as summarized in Table 4. Note that the used $v_{c}$ and $f$ values were adopted based on a compromise selection since the CFRP-phase cutting and Ti-phase cutting required different ranges of cutting parameters due to their dissimilar machinability behaviors $[6$, 19,56]. To study the frictional responses governing the hybrid CFRP/Ti cutting, different friction coefficient $\mu$ values were implemented in the FE calculation. Additionally, the fiber orientation $(\theta)$ was also taken as a key input variable for cutting modeling investigation as listed in Table 4 . Note that the selected values of the cutting parameters (cutting speed and feed rate) in Table 4 were probably low and similar to each other. However, they were consistent within the commonly used parametric ranges in real machining of hybrid CFRP/Ti stack as reported in the open literature $[5,57,58]$. During the numerical studies, several numerical and experimental comparisons were performed to validate the prediction of the FE models. 
Fig. 4 Comparison of the simulated and experimental force generation [39] in CFRP-phase cutting modeling. a Cutting force $\left(F_{c}\right)$. b Thrust force $\left(F_{t}\right)$ (cutting condition: $v_{c}=6 \mathrm{~m} / \mathrm{min}$, $f=0.2 \mathrm{~mm}$ and $\alpha=0^{\circ}$ ) (a)

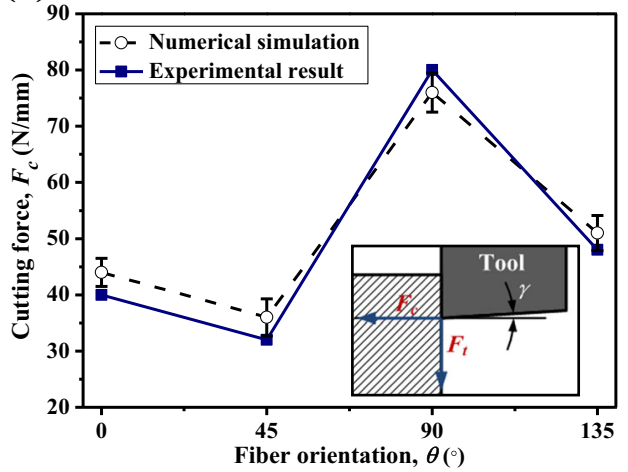

(b)

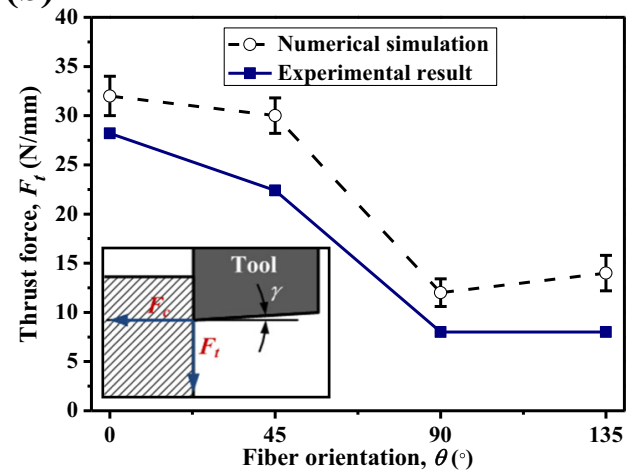

\subsection{Specific cutting energy}

In chip removal process, the friction coefficient governing the tool-work interface is a key root of various force generations occurred at tool rake face and flank face. In the following subsection, an indicator, namely, specific cutting energy $(u)$ [59], was adopted to evaluate the anisotropic machinability of the hybrid CFRP/Ti composite. The specific cutting energy $u$ $\left(J / \mathrm{cm}^{3}\right)$ signifies the cutting energy consumed to remove one unit-volume work material in machining, which is coherently determined by the mechanical properties of the studied material and can reflect its relative machinability. Specifically, in orthogonal cutting configuration, the specific cutting energy (u) can be expressed by the following equation:

$u=\frac{P_{c}}{M M R}$

where $P_{c}$ denotes the machining power, $M M R$ represents the material removal rate in $\mathrm{cm}^{3} / \mathrm{s}$ unit. In addition, the $P_{c}$ and $M M R$ can be defined by Eq. (9) and Eq. (10), respectively.

$P_{c}=F_{c} \times v_{c}$

$M M R=v_{c} \times a_{c} \times w$

where $F_{c}$ signifies the main cutting force, $v_{c}$ indicates the cutting speed, $a_{c}$ and $w$ denote the cutting depth and cutting width, respectively.

The $u$ then can be defined by Eq. (11) through the mathematical derivation of Eqs. (8), (9), and (10). Note that in the present numerical configuration, the cutting depth $\left(a_{c}\right)$

Table 4 Details of the input variables for hybrid CFRP/Ti cutting modeling

Cutting speed, $v_{c}(\mathrm{~m} / \mathrm{min})$

Feed rate, $f(\mathrm{~mm} / \mathrm{rev})$

Fiber orientation, $\theta\left(^{\circ}\right)$

Friction coefficient, $\mu$
$10,20,30,40$

$0.05,0.10,0.15,0.20$

$\theta_{i}=i \cdot d_{\theta}\left(i=0,1, \ldots, 12, d_{\theta}=15^{\circ}\right)$

$0.05,0.10,0.20,0.30,0.40$ referred to the feed rate $(f)$ while the cutting width $(w)$ equaled to $1 \mathrm{~mm}$.

$u=\frac{F_{c}}{a_{c} \times w}$

(a)

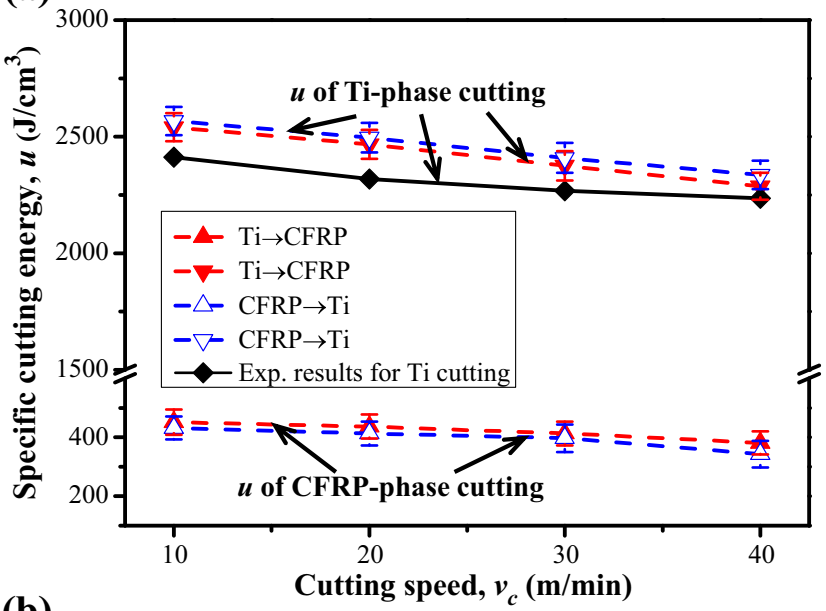

(b)

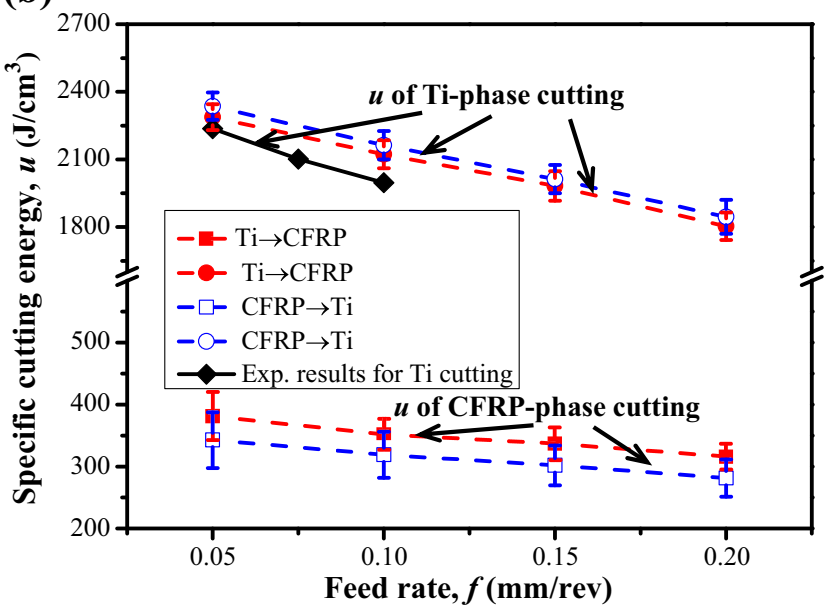

Fig. 5 Effect of the cutting parameters and cutting-sequence strategies on the specific cutting energy $(u)$ consumption when machining hybrid CFRP/Ti composite. a $u$ vs. $v_{c}\left(f=0.05 \mathrm{~mm} / \mathrm{rev}, \theta=0^{\circ}\right.$ and $\left.\mu=0.3\right)$. b $u$ vs. $f\left(v_{c}=40 \mathrm{~m} / \mathrm{min}, \theta=0^{\circ}\right.$ and $\mu=0.3$ ) (Exp. result for Ti-phase cutting extracted from Cotterell and Byrne [60]) 
Firstly, the cutting sequence's influences and cutting parameters' effects on the specific cutting energy consumption were studied. Figure 5 then shows the obtained numerical results with several comparisons to the experimental results extracted from the literature [60]. As shown in the figure, the predicted $u$ values of the Ti-phase cutting showed consistent variation trends with the experimental results extracted from the literature. The cutting sequence indeed exhibited certain effects on the specific cutting energy $(u)$ consumed in hybrid CFRP/Ti machining. Specifically, the stacked phase (e.g., Ti phase or CFRP phase) which was machined lastly in one cutting sequence typically consumed a little bit high $u$ than that performed firstly in another cutting sequence. For instance, the Ti-phase machining gave rise to more $u$ consumption in the CFRP $\rightarrow$ Ti cutting sequence than in the $\mathrm{Ti} \rightarrow$ CFRP cutting sequence. The predominant reason, as revealed in our numerical findings, showed that in either CFRP $\rightarrow$ Ti or $\mathrm{Ti} \rightarrow \mathrm{CFRP}$ cutting sequences, severe resected chip adhesion arising from the firstly cutoff phase was observed on tool rake face that substituted the main cutting edges for further chip separation and hence increased the $u$ consumption.

In addition, the cutting speed was found to have a negative impact on the specific cutting energy for both Ti-phase cutting and CFRP-phase cutting, i.e., an increased $v_{c}$ typically led to an apparently decreased $u$ consumption. The phenomenon could be associated with the thermal softening effects on the work material when $v_{c}$ was elevated. The evidence also confirmed that the high-speed cutting (HSC) might facilitate the improvement of the CFRP/Ti machinability. Besides, the impact of feed rate was also predicted to be negative. Despite the fact that an elevated $f$ typically led to an increased cutting force generation, however, the $u$ consumption was still predicted to decrease due to the reduced cutting pressure resulting from the increased uncut chip thickness. The specific mechanism could be explained by the well-known phenomenon namely as "chip size effect" [61, 62], which stated that there was a substantial reduction of the specific cutting energy with an increase of the uncut chip size. Such findings also agreed well with some experimental observations in either metal alloy cutting [61, 62] or CFRP composite cutting [48, 63] from the literature.

To inspect the frictional effect of $\mu$ on the anisotropic machinability of the hybrid composite stack, the equivalent specific cutting energy $(\bar{u})$ was introduced as expressed below.

$\bar{u}=\frac{F_{c, C F R P}+F_{c, T i}}{2 \times a_{c} \times w}$

where $F_{C, C F R P}$ and $F_{C, T i}$ denote the main cutting forces of CFRP-phase cutting and Ti-phase cutting, respectively.

Figure 6 shows the $\mu$ 's effects on the equivalent specific cutting energy $(\bar{u})$ when cutting hybrid CFRP/Ti composite under the CFRP $\rightarrow$ Ti cutting sequence. Note that in Fig. 6 , the equivalent specific cutting energy $(\bar{u})$ was plotted in a polar coordinate (polar angle $(\theta)$ versus pole diameter $(r)$ varied with the round angle range of $0 \sim 360^{\circ}$, in which the polar angle referred to the fiber orientation $(\theta)$, and the pole diameter represented the $\bar{u}$ value. The reason was that for displaying the result data in function of theta $(\theta)$ angle $\left(\theta=0 \sim 360^{\circ}\right)$, the polar coordinate commonly can easily show the activated variation law among the studied data. Besides, the results plotted in Fig. 6 also aimed to see the variation shape of the simulated $\bar{u}$ versus the fiber orientation $(\theta)$. Therefore, the polar coordinate system was adopted. For $180 \sim 360^{\circ}$ range, it could be described as fiber orientation angle $(\theta)$ subtracting $180^{\circ}$.

As depicted in Fig. 6, the $\bar{u}$ consumption during hybrid CFRP/Ti cutting exhibited strong anisotropy versus the input fiber orientation $(\theta)$, regardless of the used friction coefficient $(\mu)$. The $\bar{u}$ consumption map globally showed a "pigeon"-like shape; the $\bar{u}$ magnitudes were smaller in the second and fourth quadrants where cutting was performed in the reverse fiber direction $\left(\theta=90 \sim 180^{\circ} / 270 \sim 360^{\circ}\right)$, and larger in the first and third quadrants where cutting was performed in the forward fiber direction $\left(\theta=0 \sim 90^{\circ} / 180 \sim 270^{\circ}\right)$. Moreover, the maximum $\bar{u}$ magnitudes usually took place when cutting was operated in the perpendicular to fiber direction $\left(\theta=90^{\circ} / 270^{\circ}\right)$, which was approximately two times than that of the minimum value, forming the wings of the "pigeon"-shaped map as shown in Fig. 6a. The reason could be attributed to the severe chip separation mode governing the $90^{\circ}$ CFRP machining, which involved serious shear fracture and extrusion fracture of the chip breakage. In such case, the machinability of the CFRP/Ti stack was predicted to be the poorest in the $90^{\circ}$ fiber orientation, resulting in a large amount of $\bar{u}$ consumption. In contrast, there was slight $\bar{u}$ increase in the positions close to the horizontal axis $\left(\theta=165^{\circ} / 345^{\circ}\right)$ across the second and fourth quadrants, which formed the head and tail of the "pigeon"-shaped map as depicted in Fig. 6a. The "pigeon"-like $\bar{u}$ map, in some extent, reflected the anisotropic machinability of the hybrid CFRP/Ti stack, which depended significantly on the properties of the stacked constituents, the chip separation modes of the each phase cutting, and the anisotropy of the CFRP composite phase.

Concerning the $\mu$ 's effect, it showed significant influences on the $\bar{u}$ magnitudes of the bi-material machining. As depicted in Fig. 6, the shape and range of the specific energy map globally suffered an amplified process with the increase of $\mu$. At the minimum friction coefficient of $\mu=0.05$, the $\bar{u}$ values in various directions were the lowest, which showed the best machinability. In addition, the "amplification" trend exhibited more remarkable especially when $\mu$ increased from 0.05 to 0.30 . The phenomenon signified that in such circumstance, the frictional behavior 
Fig. 6 Effect of the friction coefficient $(\mu)$ on the equivalent consumption of hybrid CFRP/Ti composite $\left(v_{c}=40 \mathrm{~m} / \mathrm{min}\right.$ and $\mu=0.10$; (c) $\mu=0.20$; (d) $\mu=0.30$ and (e) $\mu=0.40$ specific cutting energy $(\bar{u})$ $f=0.20 \mathrm{~mm} / \mathrm{rev}$ ): (a) $\mu=0.05$; (b)
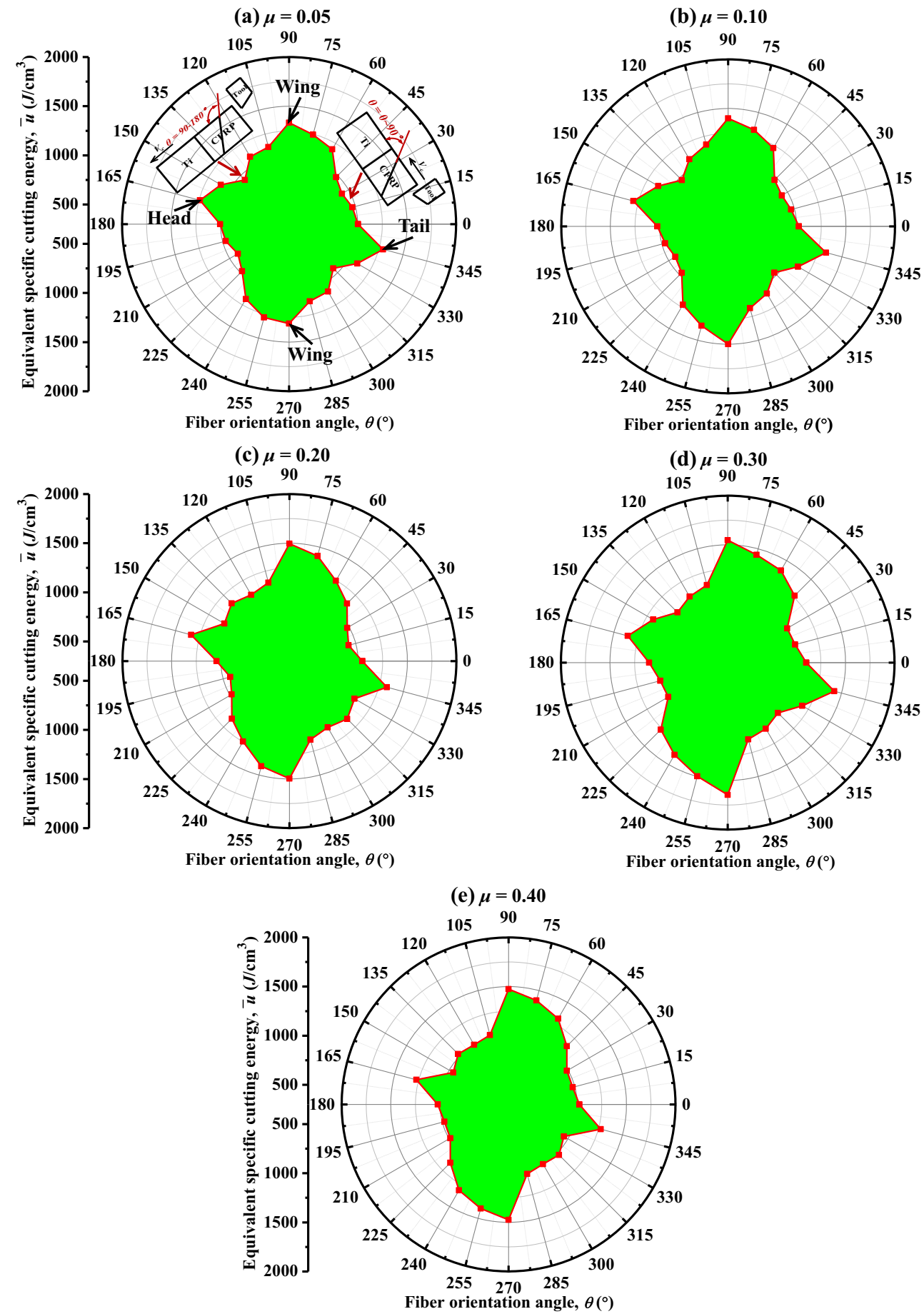

of the multi-tool-work interaction acted as a predominant role in affecting the machinability of the material. When $\mu$ reached over 0.30 , the "pigeon"-like area mostly remained the same, and more precisely, suffered a little bit shrink, as compared between Fig.6d, e, indicating the negative impact arising from $\mu$ 's behavior. Such abnormal phenomenon could be explained as follows. The actual $\mu$ 's effects on the $\bar{u}$ consumption depended significantly on the competition between the thermal softening and cutting resistance enhancement predominating the chip removal process. This meant when $\mu$ exceeded a threshold value (probably 0.30 in current case), the thermal softening due to the increased cutting temperature from elevated $\mu$, might become a dominant factor that totally affected the and hence reduced the overall $\bar{u}$ consumption. chip separation process of the hybrid CFRP/Ti composite 
Fig. 7 Machined surface morphology and induced damage in $\mathrm{CFRP} \rightarrow$ Ti cutting sequence $\left(v_{c}=40 \mathrm{~m} / \mathrm{min}, f=0.2 \mathrm{~mm} / \mathrm{rev}\right.$, $\theta=0^{\circ}$ and $\mu=0.3$ )

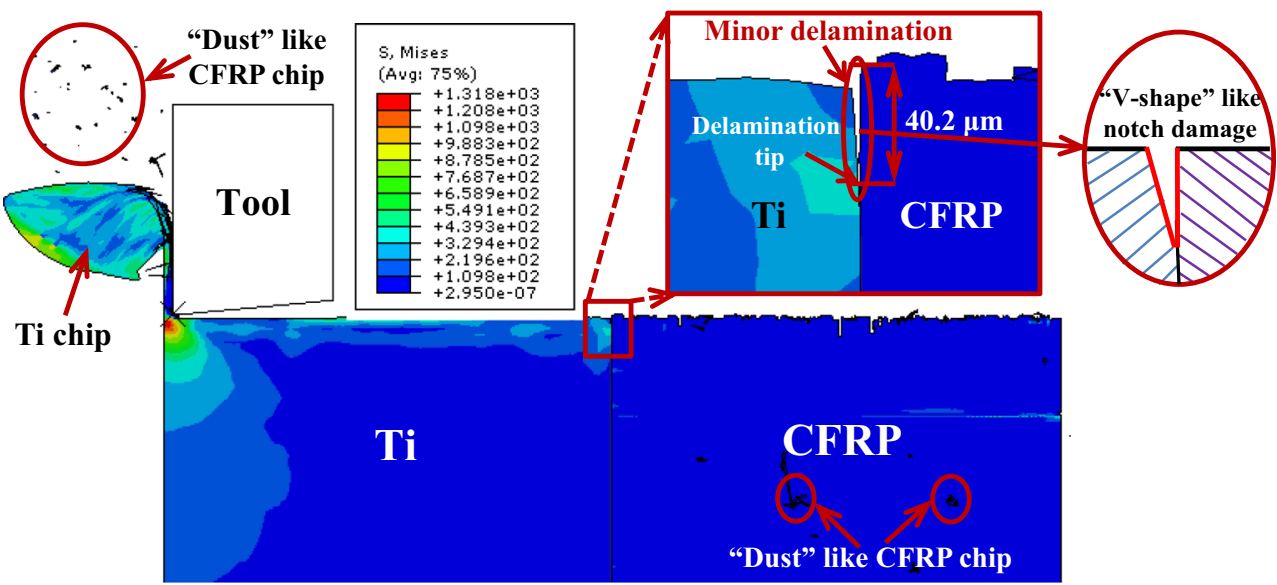

\subsection{Machined surface morphology}

In hybrid CFRP/Ti machining, severe physical damage and mechanical imperfection will be formed beneath the machined surface, which significantly affected the machined surface integrity and part quality. To clarify the cutting sequence's influence on the machined CFRP/Ti surface quality, a comparative study of the machined surface morphology was made under the identical cutting conditions $\left(v_{c}=40 \mathrm{~m} / \mathrm{min}\right.$, $f=0.2 \mathrm{~mm} / \mathrm{rev}, \theta=0^{\circ}$, and $\mu=0.3$ ).

Figures 7 and 8 then show the comparative numerical observations. It was noticeable that in hybrid CFRP/Ti cutting, different chip morphologies were generated due to the changeable tool-work interaction dominated from one-phase cutting to another phase cutting and vice versa. Such phenomenon could be attributed to the disparate natures of the "composite-to-metal" alliance. In CFRP-phase machining, the resected chip morphology appeared "dust"-like shape due to the predominant brittle-fracture chip-separation mode. Such numerical findings agreed well with the relevant experimental observations of CFRP machining [46, 64], as depicted in Fig. 9. In contrast, in Ti-phase cutting, the chip morphology was generated primarily in the form of "continuous" appearance due to the plastic-deformation chip removal mode. It should be noted that the produced Ti-chip morphology in current simulation appeared more "continuous" like rather than "serrated" like due to the use of extremely low cutting speed ( $v_{c}=40 \mathrm{~m} / \mathrm{min}$ ) that minimized the segmentation frequency of the Ti chip removal process.

Concerning the machined surface morphology, it was apparent that the machined surface finish produced in $\mathrm{CFRP} \rightarrow \mathrm{Ti}$ cutting sequence appeared much smoother than that operated in $\mathrm{Ti} \rightarrow \mathrm{CFRP}$ cutting sequence. Moreover, only minor crack damage was detected beneath the machined CFRP surface in the CFRP $\rightarrow$ Ti cutting sequence as shown in Fig. 7. In contrast, the $\mathrm{Ti} \rightarrow \mathrm{CFRP}$ cutting sequence promoted serious crack imperfections concerning the CFRP-phase machined surface. Furthermore, the CFRP surface generated in the $\mathrm{Ti} \rightarrow \mathrm{CFRP}$ cutting sequence appeared extremely uneven

Fig. 8 Machined surface morphology and induced damage in $\mathrm{Ti} \rightarrow \mathrm{CFRP}$ cutting sequence $\left(v_{c}=40 \mathrm{~m} / \mathrm{min}, f=0.2 \mathrm{~mm} / \mathrm{rev}\right.$, $\theta=0^{\circ}$ and $\mu=0.3$ )

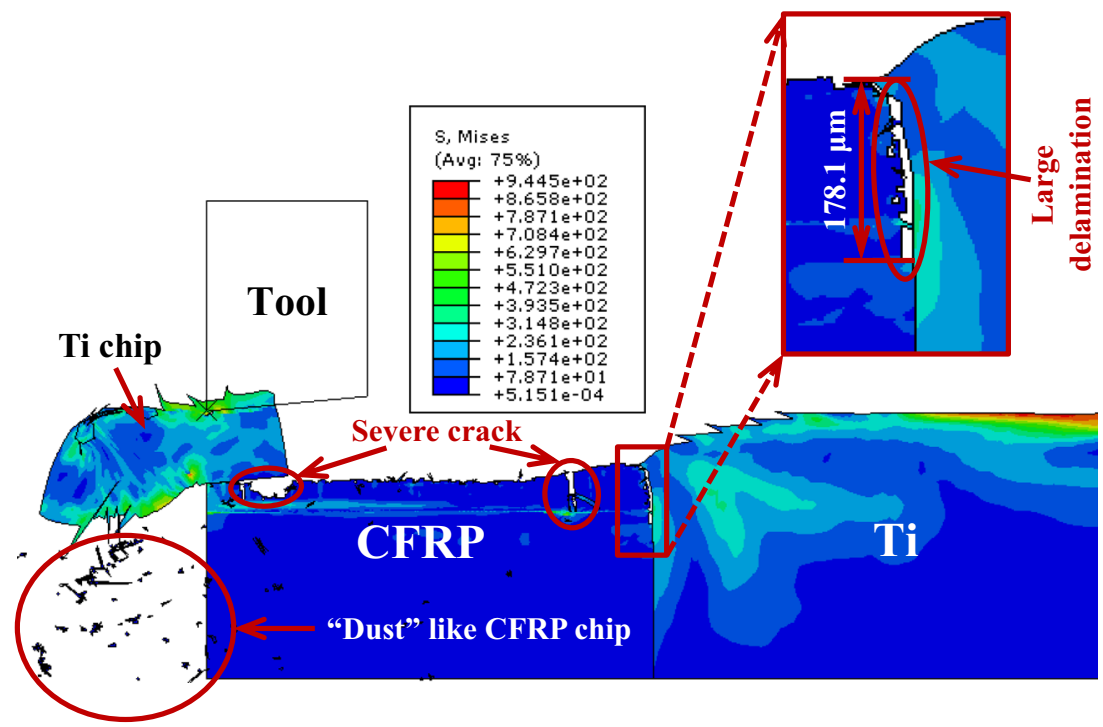



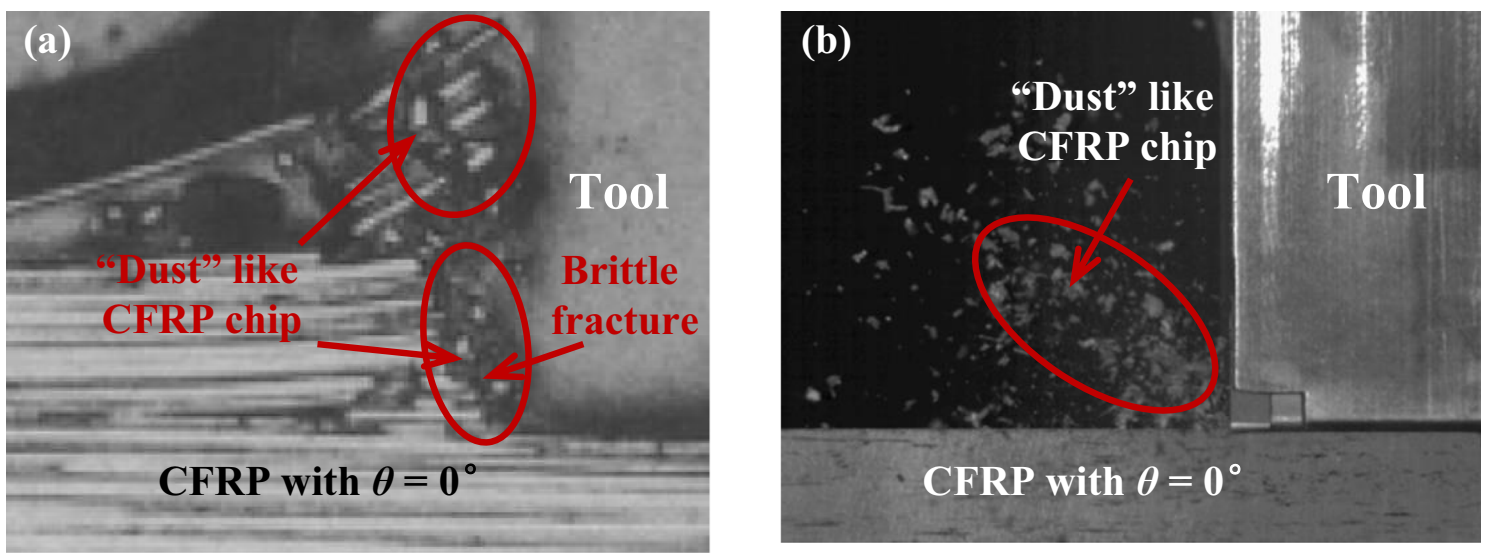

Fig. 9 Experimental observation of the resected chip morphology when orthogonal cutting of CFRP laminates with $0^{\circ}$ fiber orientation. a High-speed video image from Koplev et al. [46]. b High-speed video image from Mkaddem et al. [64]

and rough as compared to that obtained in the CFRP $\rightarrow$ Ti cutting sequence. Such phenomenon could be due to the serious Ti-chip adhesion on tool rake face that caused serious scratching effects on the machined CFRP surface.

With respect to the interface zone, the "CFRP-to-Ti" contact boundary should be the weakest region vulnerable to serious subsurface damage formation during the hybrid composite machining due to the unstable chip-separation mode dominated and the severe mechanical/physical charge transfer occupied. As revealed in our previous research work $[8,30]$, the interface damage usually takes place in the form of delamination imperfection due to the specific cutting loads exerted on the "CFRP-to-Ti" contact boundary when the tool edges cut from one phase to another phase and vice versa. Specifically, the activated mechanisms could be attributed to the combined effects of both fracture mode I and fracture mode II exerted on

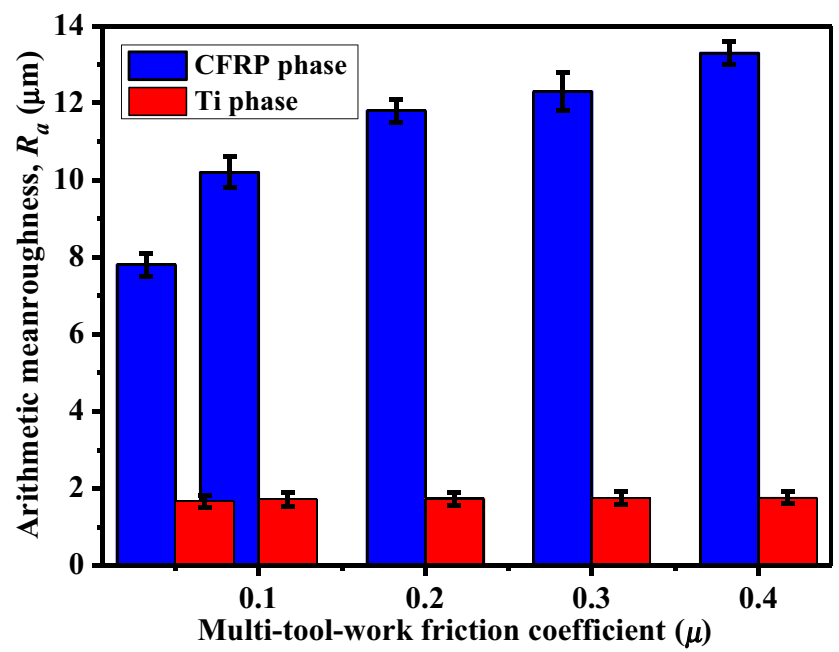

Fig. 10 Effect of the multi-tool-work friction coefficient $(\mu)$ on the arithmetic mean roughness $\left(R_{a}\right)$ when cutting hybrid CFRP/Ti composite $\left(v_{c}=40 \mathrm{~m} / \mathrm{min}, f=0.2 \mathrm{~mm} / \mathrm{rev}, \theta=0^{\circ}\right.$ and CFRP $\rightarrow \mathrm{Ti}$ cutting sequence) the interface region $[8,30]$. The key manifestation of the delamination morphology was usually a "V"-shape notch concentrated on the bi-material interface [30], as shown schematically in magnified interface zone of Fig. 7. Moreover, in $\mathrm{Ti} \rightarrow$ CFRP cutting sequence, typically a large length of delamination extent was produced focused on the bi-material interface. The predicted delamination length $\left(D_{d e l}=178.1 \mu \mathrm{m}\right)$ was approximately 4.43 times longer than that $\left(D_{\text {del }}=40.2 \mu \mathrm{m}\right)$ generated in CFRP $\rightarrow$ Ti cutting sequence. The reason could be explained by the fact that in CFRP $\rightarrow$ Ti cutting sequence, the Ti alloy could act as the role of supporting plate in preventing the CFRP laminate inflection and ensuring the stability of the multi-tool-work interaction during the cutting operation. As a result, low extent of interface delamination was promoted. In contrast, when operated in the $\mathrm{Ti} \rightarrow \mathrm{CFRP}$ cutting sequence, the CFRP phase could not act the role of supporting plate when the tool firstly cut into the Ti phase and subsequently into the interface region due to its inherent brittleness. Consequently, a high extent of delamination damage was produced in such circumstance.

To inspect the $\mu$ 's effects on the machined CFRP/Ti surface quality, the most-used one-dimensional arithmetic mean roughness $\left(R_{a}\right)$ was introduced for the comparative studies under the reasonable $\mathrm{CFRP} \rightarrow \mathrm{Ti}$ cutting sequence as discussed above. Note that for each machined-phase surface, nearly $N=100$ sampling nodes were selected on the machined surface within the sample length ( $L=1-\mathrm{mm}$ cutting length). Each measurement was repeated three times in order to ensure the sufficient credibility of the acquired results.

Figure 10 shows the $\mu$ 's effects on the simulated $R_{a}$ of each machined surface (CFRP phase and Ti phase) when cutting hybrid CFRP/Ti composite $\left(\theta=0^{\circ}\right.$, $v_{c}=40 \mathrm{~m} / \mathrm{min}$ and $f=0.2 \mathrm{~mm} / \mathrm{rev}$ ). It was apparent that the $\mu$ had pronounced effects on the $R_{a}$ of CFRP surface in such manner that an increase of $\mu$ commonly gave rise to an obviously elevated $R_{a}$ value. The phenomenon indicated that high friction coefficient 
Fig. 11 Scheme of the composite-phase damage $\left(D_{C F R P}\right)$ measurement when cutting hybrid CFRP/Ti (note: HSNMCCRT indicates the matrix-compression failure)

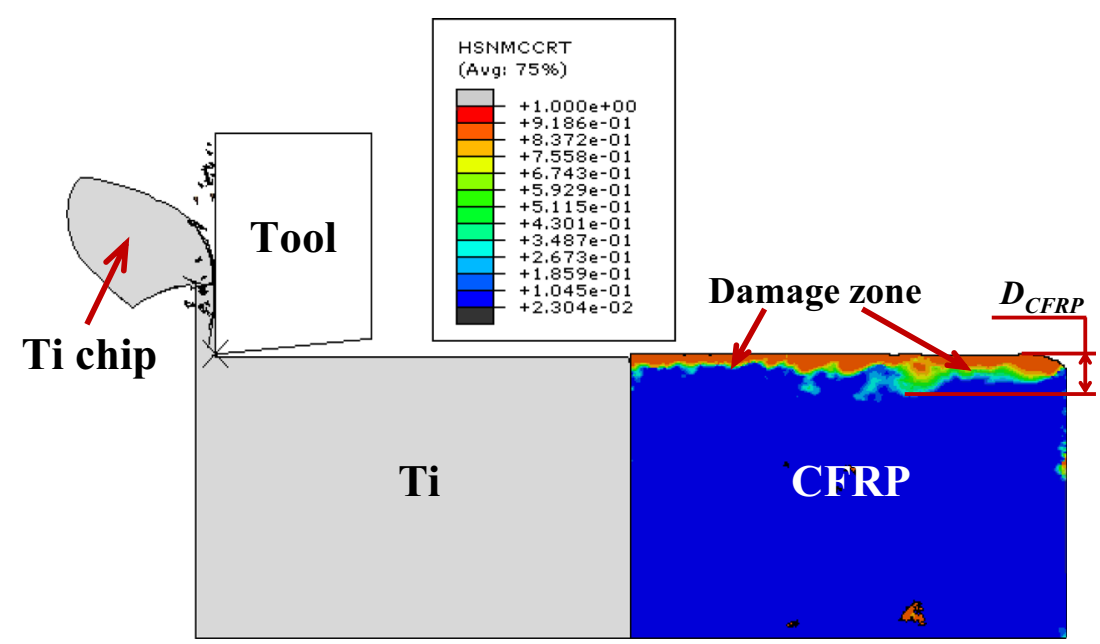

controlling the multi-tool-work interaction would deteriorate the machined surface quality. This was because when $\mu$ was elevated, high cutting resistance and high heat generation would predominate the chip removal process that resulted in the poor machinability of the workpiece and consequently severe damage formation on the machined surface. As a consequence, the machined surface finish was destroyed greatly and thus led to the high surface roughness. In contrast, the $\mu$ 's effects on the $R_{a}$ of the Ti-phase surface seemed to be insignificant. The simulated $R_{a}$ values mostly remained the same in terms of the $\mu$ 's variation. It should be noted that the mesh size effects had affected the $R_{a}$ measurement in the current simulation. For Ti phase, the mesh size was set around $10 \mu \mathrm{m}$, which was much higher than its commonly generated $R_{a}$-value range. In such circumstance, the $R_{a}$ value was estimated to be affected slightly by the $\mu$ 's variation during the simulation process. Despite all that, the generated $R_{a}$ values of the Ti phase surface were all lower than those of the machined CFRP surface, regardless of the implemented $\mu$ values. This was because, in Ti-phase cutting, the predominant chip-separation mode was elastic-plastic deformation that produced "continuous" chip type and thus favored the generation of smooth surface finish. By contrast, the brittle-fracture chip-separation mode governing the CFRP-phase cutting usually resulted in severe micro-crack or micro-fracture on/beneath the machined surface, which significantly deteriorated the machined surface finish and thus gave rise to high $R_{a}$ values.

\subsection{Frictional effects on induced damage extent and machined surface integrity}

As illustrated in subsection 4.2 , the $\mathrm{CFRP} \rightarrow \mathrm{Ti}$ cutting sequence was confirmed to be the reasonable cutting strategy favoring the hybrid CFRP/Ti machining. Therefore, the following numerical simulations were performed under this optimal cutting sequence. To inspect the effects of both multitool-work friction coefficient and the input cutting parameters on the cutting-induced damage extent, special emphases were made on the analyses of composite-phase damage, interface delamination, and the induced residual stress, respectively. Note that since there exist four types of fiber/matrix damage in the laminated CFRP machining, the composite-phase
Fig. 12 Effect of the multi-toolwork friction coefficient $(\mu)$ on the composite-phase damage extent $\left(D_{C F R P}\right)\left(v_{c}=40 \mathrm{~m} / \mathrm{min}\right.$, $f=0.2 \mathrm{~mm} / \mathrm{rev}$ and CFRP $\rightarrow \mathrm{Ti}$ cutting sequence)

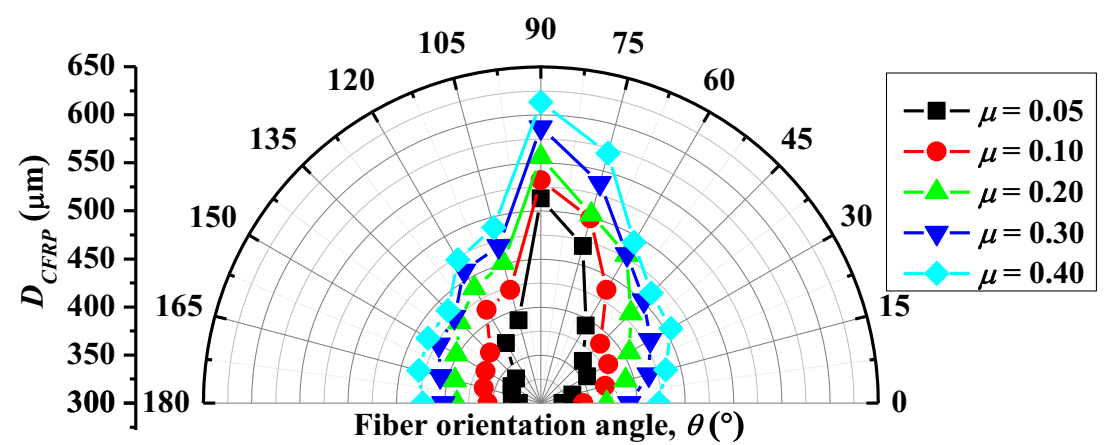


Fig. 13 Effect of the multi-toolwork friction coefficient $(\mu)$ on the interface delamination extent $\left(D_{d e l}\right)\left(v_{c}=40 \mathrm{~m} / \mathrm{min}, f=0.2 \mathrm{~mm} /\right.$ rev and CFRP $\rightarrow$ Ti cutting sequence)

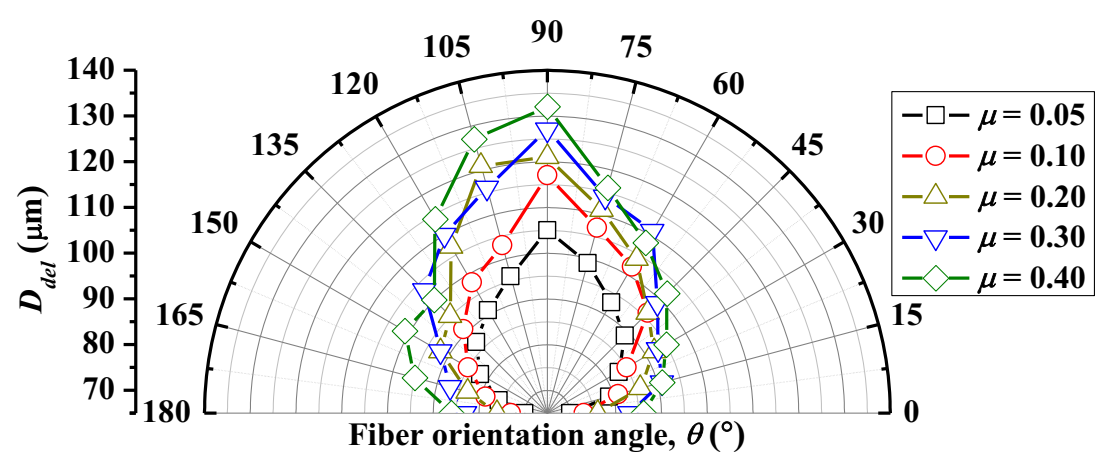

damage $\left(D_{C F R P}\right)$ was assessed based on the type that caused the largest extent of failure. Afterward, the $D_{C F R P}$ was measured as the largest length from the machined CFRP surface to the deepest damaged area, as shown schematically in Fig. 11. For the interface delamination $\left(D_{d e l}\right)$, it was measured as the maximum length from the nominal machined surface to the delamination tip as shown schematically in the magnified interface zone of Fig. 7. The residual stress of the machined $\mathrm{Ti}$ phase was measured as a function of depth from the machined surface. All the simulations were performed under the optimal $\mathrm{CFRP} \rightarrow$ Ti cutting sequence. Each measurement was repeated at least three times in order to ensure the sufficient credibility of the acquired results.

Figures 12 and 13 show the influences of the multitool-work friction coefficient $(\mu)$ on the two types of cutting-induced damage extents $\left(D_{C F R P}\right.$ and $\left.D_{d e l}\right)$ under the fixed cutting conditions of $v_{c}=40 \mathrm{~m} / \mathrm{min}$ and $f=0.20 \mathrm{~mm} / \mathrm{rev}$, respectively. These two figures were also plotted in a coordinate system to show clearly the variation law of the predicted cutting-induced damage extent $\left(D_{C F R P}\right.$ and $\left.D_{d e l}\right)$ versus the fiber orientation $(\theta)$. It was noticeable that the $\mu$ had pronounced effects on the extent of $D_{C F R P}$ and $D_{d e l}$. At the maximum friction coefficient of 0.40 , all the induced damage extent in various fiber orientations was the highest, indicating the poorest machined surface quality. The reason dominating the damage variation could be attributed to the enhanced thermal-mechanical loads exerted on the machined surface when $\mu$ was elevated. The fiber orientation $(\theta)$, however, was observed to have anisotropic effects on the $D_{C F R P}$ and $D_{d e l}$. Such influence showed the similar variation trend as it is on the equivalent specific cutting energy $(\bar{u})$, in which the minimum/maximum damage extent was produced at $\theta=0^{\circ} / 90^{\circ}$, respectively. Moreover, the cutting speed was found to globally have a negative impact on the $D_{C F R P}$ and $D_{\text {del }}$ extents (except the abnormal point of $v_{c}=10 \mathrm{~m} / \mathrm{min}$ for $D_{d e l}$ ) while the impact of feed rate was totally positive, as depicted in Fig. 14. Besides, a combination of high cutting speed and low feed rate commonly resulted in the minimalinduced damage formation.
Furthermore, for the machined Ti-phase surface, the induced residual stress commonly used for surfaceintegrity evaluation of metal alloy cutting was studied versus the multi-tool-work friction coefficient $(\mu)$. Note that the residual stress was measured in the middlelength region of the machined Ti-phase (as shown schematically in the region II of the machined Ti surface in Fig. 15 (b)), where the cutting operation could be

(a)

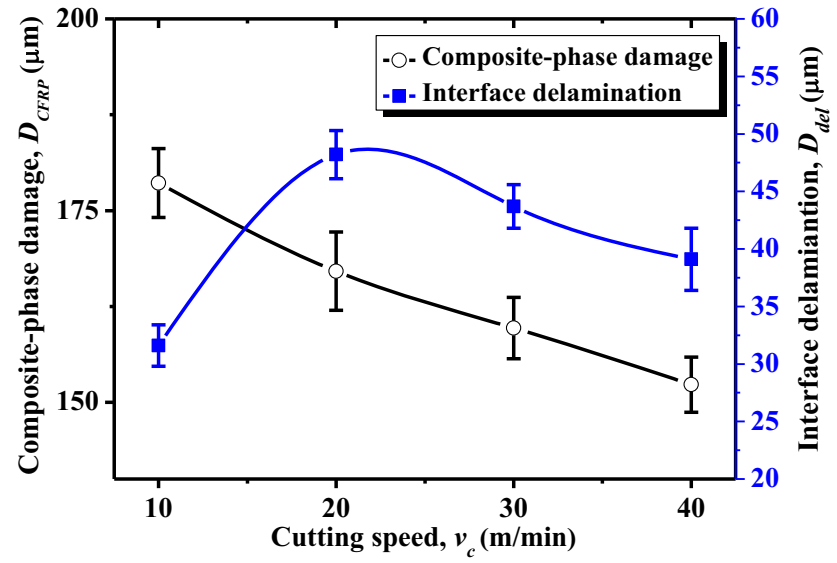

(b)

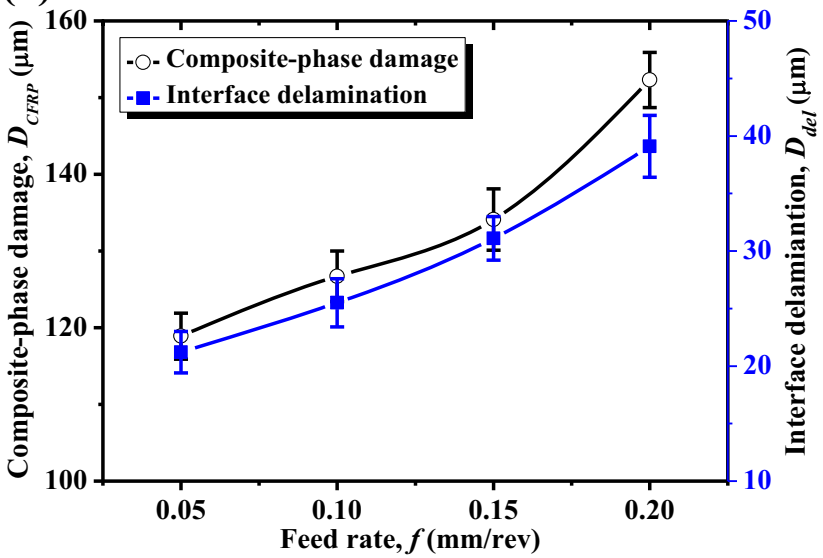

Fig. 14 Parametric effect of a cutting speed $\left(v_{c}\right)\left(f=0.2 \mathrm{~mm} / \mathrm{rev}, \theta=0^{\circ}\right.$ and $\mu=0.3)$ and $\mathbf{b}$ feed rate $(f)\left(v_{c}=40 \mathrm{~m} / \mathrm{min}, \theta=0^{\circ}\right.$ and $\left.\mu=0.3\right)$ on $D_{C F R P}$ and $D_{d e l}$ 
Fig. 15 a Effect of the multitool-work friction coefficient $(\mu)$ on the residual stress profile of the machined Ti-phase surface when cutting hybrid CFRP/Ti

composite $\left(v_{c}=40 \mathrm{~m} / \mathrm{min}\right.$, $f=0.2 \mathrm{~mm} / \mathrm{rev}, \theta=0^{\circ}$ and $\mathrm{CFRP} \rightarrow$ Ti cutting sequence). $\mathbf{b}$ Scheme of the residual stress measurement in the machined $\mathrm{Ti}$ surface (region $\mathrm{I} \rightarrow$ the onset of the Ti-phase cutting; region II $\rightarrow$ the steady state of the Ti-phase cutting and region III $\rightarrow$ the exit of the Ti-phase cutting)

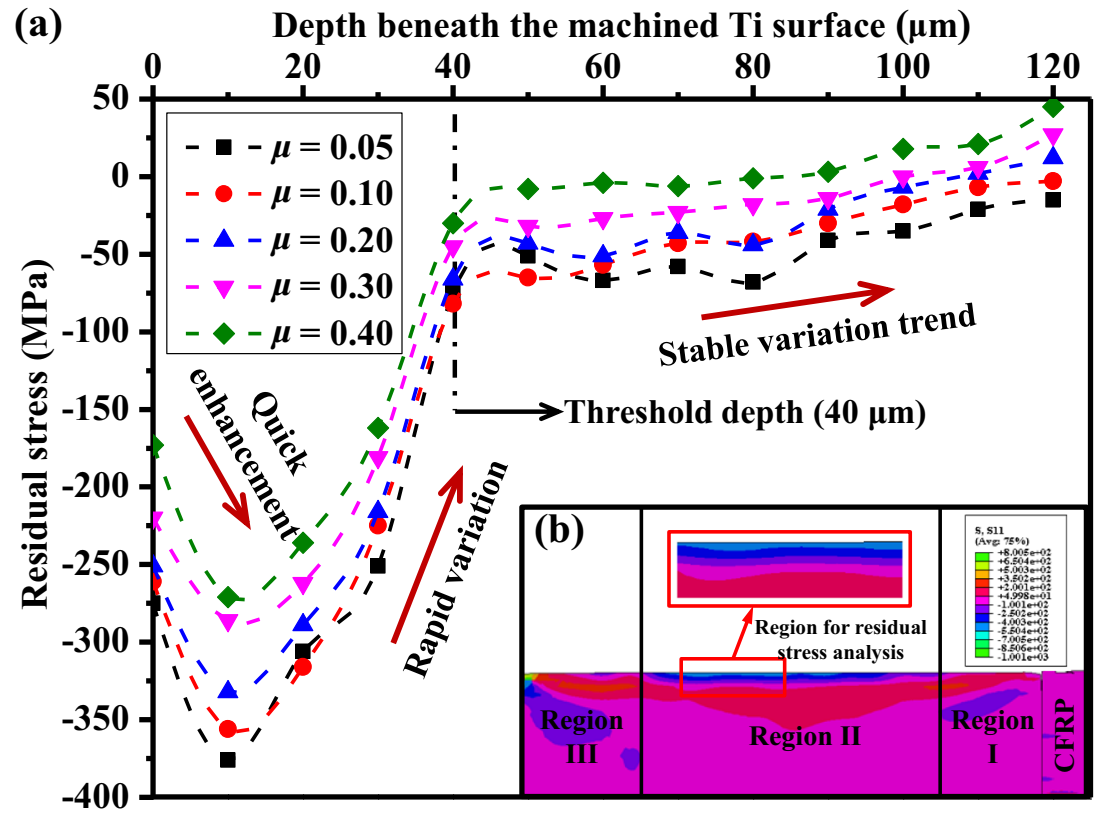

assumed to reach a steady state. Figure $15 \mathrm{a}$ then presents $\mu$ 's effects on the residual stress distribution beneath the machined surface. It can be seen that the residual stresses remained on the machined surface ( $0 \mu \mathrm{m}$ depth) were predicted to be negative regardless of the used friction coefficients, indicating the presence of compressive stresses. With the increase of depth, the compressive stresses firstly experienced an enhanced process within the depth range of $0 \sim 10 \mu \mathrm{m}$. Afterward, the compressive stresses were found to suffer significant reduction versus the increased depth. Besides, a threshold depth $(40 \mu \mathrm{m})$ was also detected, beyond which, the residual stresses basically reached a stable state accompanied by very slight variation, implying the minimal influences arising from the cutting process. Moreover, the acquired results presented in Fig.15a also clearly proved that the $\mu$ had significant influences on the residual stress profile of the Ti phase. An increase of $\mu$ usually gave rise to the increased tensile stresses and decreased compression stresses. From the viewpoint of the fatigue performance of the machined parts, the compressive stresses contribute to the fatigue life while the tensile stresses exhibit destructive for surface integrity and thus should be strongly avoided [65]. The detrimental effects implied that the multi-tool-work frictional behavior affected the residual stress distribution primarily via its thermal influence rather than its mechanical effects. That meant when $\mu$ increased, a large amount of cutting heat would be generated along the tool-work interface and hence transferred on the machined Ti surface. Consequently, the highly increased cutting temperature resulted in the enhancement of the tensile stresses while the reduction of the compressive stresses. In such circumstance, the machined surface integrity was deteriorated significantly.

The above analyses demonstrated that for improving the machined surface quality, small multi-tool-work friction coefficient as well as low fiber orientation, high cutting speed, and low feed rate should be preferentially selected under the tested parametric ranges when cutting hybrid CFRP/Ti composite. The $\mu$ 's effect on the residual stresses of the machined Ti-phase surface was totally detrimental, indicating the predominant factor was the thermal influence. For realizing the improvement of the multi-tool-work frictional behavior, i.e., reducing $\mu$, typically the application of effective cutting fluid and the usage of superior tool material could be adopted in the real production of the stacked composite.

\section{Conclusions}

In this paper, a multi-physical model was developed to address the fundamental frictional responses of hybrid CFRP/Ti machining. The numerical studies shed light on several implicit cutting physics of the stacked composite and hence offered an enhanced cutting comprehension. Based on the results acquired, the key findings can be drawn as follows.

(1) The multi-tool-work friction coefficient $(\mu)$ played a crucial role in affecting the various frictional responses of hybrid CFRP/Ti machining via its thermal and mechanical influences. However, for specific machining response, the $\mu$ 's effect depended 
significantly on which factor (thermal or mechanical influences) predominated the affecting process. In such case, different mechanisms were observed in the current numerical studies. For cutting energy consumption, the $\mu$ 's influence primarily depended on the competition between the thermal softening and cutting-resistance enhancement governing the chip separation process when $\mu$ was elevated. A threshold $\mu$ value was predicted around 0.3 , beyond which, the $\mu$ 's impact on $\bar{u}$ consumption was negative due to the increased thermal softening over cutting-resistance enhancement when $\mu$ increased. In addition, the $\mu$ also exhibited significantly positive impacts on the induced subsurface damage formation (composite-phase damage and interface delamination) owing to the enhanced thermal-mechanical loads exerted on the machined surface when $\mu$ was elevated. With respect to the induced residual stresses of the machined Ti part, the predominant factor governing the $\mu$ 's influences were thermal effects that contributed to the enhancement of tensile stresses while the reduction of compressive stresses.

(2) Cutting-sequence strategy was confirmed to have significant effects on the hybrid cutting process. For minimizing the specific cutting energy consumption and improving the machined surface quality, the reasonable $\mathrm{CFRP} \rightarrow$ Ti cutting sequence should be preferentially adopted when machining hybrid CFRP/Ti composite.

(3) The parametric studies highlighted that the fiber orientation $(\theta)$ was a notable factor leading to the anisotropic machinability of the hybrid CFRP/Ti composite. Cutting parameters $\left(v_{c}\right.$ and $\left.f\right)$ exhibited significant effects on the specific cutting energy consumption and affected subsurface damage extent. Moreover, a combination of highspeed and high-feed cutting was found to facilitate the reduction of the $u$ consumption.

(4) The numerical studies pointed out that improving the multi-tool-work frictional behavior, i.e., reducing $\mu$, would be a direct solution to achieving high-quality machining of hybrid CFRP/Ti composite. To this aim, several applications capable of reducing $\mu$, like the use of effective cutting fluid and superior tool material, can be adopted in the real production of the stacked material. Moreover, for improving the machined surface quality, the high cutting speed, low feed rate, and small fiber orientation should be adopted when cutting hybrid CFRP/Ti composite.

This paper made an attempt to study the complicated frictional responses governing the hybrid CFRP/Ti cutting via the numerical method. However, the proposed FE model was established based on the assumption of orthogonal cutting configuration (OCC) and ignored some complex details of the multi-tool-work interaction presented in real machining (e.g., drilling or milling). Besides, the tool used in FE modeling was assumed as a rigid body and tool wear was thereby neglected, which was commonly an important issue involved in real hybrid CFRP/Ti machining. Nevertheless, the current numerical work could be considered as a tentative effort to numerically address the basic cutting physics governing the hybrid CFRP/Ti machining. To study the in-depth cutting mechanisms and also to reflect accurately the real manufacturing operation, more sophisticated models by considering rigorously the physical details of the multi-tool-work interaction (e.g., tool behavior, tool wear) are critically demanded. Moreover, in the future, a combined research of both numerical simulation and experimentation should also be performed to offer an improved CFRP/Ti cutting comprehension.

Acknowledgments The authors gratefully acknowledge the financial support of the China Scholarship Council (CSC) (Contract No. 201306230091)

\section{References}

1. Zhang L, Liu Z, Tian W, Liao W (2015) Experimental studies on the performance of different structure tools in drilling CFRP/Al alloy stacks. Int J Adv Manuf Technol 81(1):241-251

2. Luo B, Li Y, Zhang K, Cheng H, Liu S (2015) A novel prediction model for thrust force and torque in drilling interface region of CFRP/Ti stacks. Int J Adv Manuf Technol 81(9-12):1497-1508

3. Montoya M, Calamaz M, Gehin D, Girot F (2013) Evaluation of the performance of coated and uncoated carbide tools in drilling thick CFRP/aluminium alloy stacks. Int J Adv Manuf Technol 68(9-12): 2111-2120

4. Xu J, Mkaddem A, El Mansori M (2016) Recent advances in drilling hybrid FRP/Ti composite: a state-of-the-art review. Compos Struct 135:316-338

5. Ramulu M, Branson T, Kim D (2001) A study on the drilling of composite and titanium stacks. Compos Struct 54(1):67-77

6. Park KH, Beal A, Kim D, Kwon P, Lantrip J (2011) Tool wear in drilling of composite/titanium stacks using carbide and polycrystalline diamond tools. Wear 271(11-12):2826-2835

7. Park KH, Beal A, Kim D, Kwon P, Lantrip J (2014) A comparative study of carbide tools in drilling of CFRP and CFRP-Ti stacks. J Manuf Sci Eng-Trans ASME 136(1):014501

8. Xu J, El Mansori M (2015) Cutting modeling using cohesive zone concept of titanium/CFRP composite stacks. Int J Precis Eng Manuf 16(10):2091-2100

9. Liu D, Tang Y, Cong WL (2012) A review of mechanical drilling for composite laminates. Compos Struct 94(4):1265-1279

10. Che D, Saxena I, Han P, Guo P, Ehmann KF (2014) Machining of carbon fiber reinforced plastics/polymers: a literature review. J Manuf Sci Eng-Trans ASME 136(3):034001

11. Ezugwu EO, Wang ZM (1997) Titanium alloys and their machinability - a review. J Mater Process Technol 68(3):262-274

12. Ezugwu EO, Bonney J, Da Silva RB, Cakir O (2007) Surface integrity of finished turned Ti-6Al-4V alloy with PCD tools using conventional and high pressure coolant supplies. Int J Mach Tools Manuf 47(6):884-891 
13. Nurul Amin AKM, Ismail AF, Nor Khairusshima MK (2007) Effectiveness of uncoated WC-Co and PCD inserts in end milling of titanium alloy-Ti-6Al-4V. J Mater Process Technol 192:147158

14. Liu Z, An Q, Xu J, Chen M, Han S (2013) Wear performance of (nc-AlTiN)/(a-Si $\left.\mathrm{N}_{4}\right)$ coating and (nc-AlCrN)/(a-Si $\left.{ }_{3} \mathrm{~N}_{4}\right)$ coating in high-speed machining of titanium alloys under dry and minimum quantity lubrication (MQL) conditions. Wear 305(1-2):249-259

15. Wika KK, Sharman ARC, Goulbourne D, Ridgway K (2011) Impact of number of flutes and helix angle on tool performance and hole quality in drilling composite/titanium stacks. SAE 2011 AeroTech Congress and Exhibition. Toulouse

16. SenthilKumar M, Prabukarthi A, Krishnaraj V (2013) Study on tool wear and chip formation during drilling carbon fiber reinforced polymer (CFRP)/titanium alloy (Ti6Al4V) stacks. Procedia Engineering 64:582-592

17. Garrick R (2007) Drilling advanced aircraft structures with PCD (poly-crystalline diamond) drills. Paper presented at the AeroTech congress and exhibition, Los Angeles, CA, USA, 18-20 September

18. Kuo CL, Soo SL, Aspinwall DK, Bradley S, Thomas W, M'Saoubi R, Pearson D, Leahy W (2014) Tool wear and hole quality when single-shot drilling of metallic-composite stacks with diamondcoated tools. Proc Inst Mech Eng Pt B-J Eng Manuf 228(10): 1314-1322

19. Kim D, Ramulu M (2004) Drilling process optimization for graphite/bismaleimide-titanium alloy stacks. Compos Struct 63(1):101-114

20. Kim D, Ramulu M (2005) Machinability of titanium/graphite hybrid composites in drilling. Trans North Am Manuf Res Inst SME 33:445-452

21. Fujiwara J, Nagaura R, Kuroda K, Tashiro T (2012) Drilling of CFRP/Ti6Al4V stack board. Paper presented at the Proc 16th International Conference on Mechatronics Technology, Tianjin, China, 16-19 October

22. Arola D, Ramulu M (1997) Orthogonal cutting of fiber-reinforced composites: a finite element analysis. Int J Mech Sci 39(5):597-613

23. Ramesh MV, Seetharamu KN, Ganesan N, Sivakumar MS (1998) Analysis of machining of FRPs using FEM. Int J Mach Tools Manuf 38(12):1531-1549

24. Mahdi M, Zhang L (2001) A finite element model for the orthogonal cutting of fiber-reinforced composite materials. J Mater Process Technol 113(1-3):373-377

25. Bhatnagar N, Nayak D, Singh I, Chouhan H, Mahajan P (2004) Determination of machining-induced damage characteristics of fiber reinforced plastic composite laminates. Mater Manuf Process 19(6):1009-1023

26. Rao GVG, Mahajan P, Bhatnagar N (2008) Three-dimensional macro-mechanical finite element model for machining of unidirectional-fiber reinforced polymer composites. Mater Sci Eng A 498(1-2):142-149

27. Mkaddem A, Demirci I, El Mansori M (2008) A micro-macro combined approach using FEM for modelling of machining of FRP composites: cutting forces analysis. Compos Sci Technol 68(1516):3123-3127

28. Xi Y, Bermingham M, Wang G, Dargusch M (2013) Finite element modeling of cutting force and chip formation during thermally assisted machining of Ti6Al4V alloy. J Manuf Sci Eng-Trans ASME 135(6):061014

29. Chen G, Ren C, Yang X, Jin X, Guo T (2011) Finite element simulation of high-speed machining of titanium alloy (Ti-6Al-4V) based on ductile failure model. Int J Adv Manuf Technol 56(9-12): 1027-1038

30. Xu J, El Mansori M (2016) Cutting modeling of hybrid CFRP/Ti composite with induced damage analysis. Materials 9(1):22
31. Xu J, El Mansori M (2016) Numerical modeling of stacked composite CFRP/Ti machining under different cutting sequence strategies. Int J Precis Eng Manuf 17(1):99-107

32. Lasri L, Nouari M, El Mansori M (2009) Modelling of chip separation in machining unidirectional FRP composites by stiffness degradation concept. Compos Sci Technol 69(5):684-692

33. Lasri L, Nouari M, El Mansori M (2011) Wear resistance and induced cutting damage of aeronautical FRP components obtained by machining. Wear 271(9-10):2542-2548

34. Arola D, Sultan MB, Ramulu M (2002) Finite element modeling of edge trimming fiber reinforced plastics. J Manuf Sci Eng-Trans ASME 124(1):32-41

35. Hocheng H, Puw HY, Huang Y (1993) Preliminary study on milling of unidirectional carbon fibre-reinforced plastics. Compos Manuf 4(2): 103-108

36. Wang DH, Ramulu M, Arola D (1995) Orthogonal cutting mechanisms of graphite/epoxy composite. Part I: unidirectional laminate. Int J Mach Tools Manuf 35(12):1623-1638

37. Zorev NN (1963) Inter-relationship between shear processes occurring along tool face and shear plane in metal cutting. Int Res Prod Eng 49:42-49

38. Iliescu D (2008) Approches experimentale et numerique de l'usinage a sec des composites carbone-epoxy. PhD Dissertation, Arts et Métiers ParisTech, French

39. Iliescu D, Gehin D, Iordanoff I, Girot F, Gutiérrez ME (2010) A discrete element method for the simulation of CFRP cutting. Compos Sci Technol 70(1):73-80

40. Aymerich F, Dore F, Priolo P (2008) Prediction of impact-induced delamination in cross-ply composite laminates using cohesive interface elements. Compos Sci Technol 68(12):2383-2390

41. Savani E, Pirondi A, Carta F, Nogueira AC, Hombergsmeier E (2012) Modeling delamination of Ti-CFRP interfaces. Paper presented at the 15th European Conference on Composite Materials, Venice, Italy, 24-28 June

42. Jensen HM (1990) Mixed mode interface fracture criteria. Acta Mater 38(12):2637-2644

43. Johnson GR, Cook WH (1983) A constitutive model and data for metals subjected to large strains, high strain rates and high temperatures. In. Proc. of the 7th International Symposium on Ballistics, 1983. The Netherlands, pp 541-547

44. Johnson GR, Cook WH (1985) Fracture characteristics of three metals subjected to various strains, strain rates, temperatures and pressures. Eng Fract Mech 21(1):31-48

45. Lesuer D (1999) Experimental investigation of material models for Ti-6Al-4V and 2024-T3. University of California, Lawrence Livermore National Laboratory, Livermore

46. Koplev A, Lystrup A, Vorm T (1983) The cutting process, chips, and cutting forces in machining CFRP. Compos 14(4):371-376

47. Pwu H, Hocheng H (1998) Chip formation model of cutting fiberreinforced plastics perpendicular to fiber axis. J Manuf Sci EngTrans ASME 120(1):192-196

48. Sreejith PS, Krishnamurthy R, Malhotra SK, Narayanasamy K (2000) Evaluation of PCD tool performance during machining of carbon/phenolic ablative composites. J Mater Process Technol 104(1):53-58

49. Hashin Z, Rotem A (1973) A fatigue failure criterion for fiber reinforced materials. J Compos Mater 7(4):448-464

50. Hashin Z (1980) Failure criteria for unidirectional fiber composites. J Appl Mech - Trans ASME 47(2):329-334

51. Fish JC, Lee SW (1989) Delamination of tapered composite structures. Eng Fract Mech 34(1):43-54

52. Hou J, Petrinic N, Ruiz C, Hallett S (2000) Prediction of impact damage in composite plates. Compos Sci Technol 60(2):273-281

53. Benzeggagh ML, Kenane M (1996) Measurement of mixed-mode delamination fracture toughness of unidirectional glass/epoxy 
composites with mixed-mode bending apparatus. Compos Sci Technol 56(4):439-449

54. Lapczyk I, Hurtado JA (2007) Progressive damage modeling in fiber-reinforced materials. Compos Pt A - Appl Sci Manuf 38(11): 2333-2341

55. Gentel A, Hoffmeister HW (2001) Chip formation in machining Ti6A14V at extremely high cutting speeds. CIRP Ann - Manuf Technol 50(1):14-17

56. Park KH, Kwon PY, Castro G, Kim D, Lantrip J (2010) Preliminary study on tool wear in drilling of composite/titanium stacks with carbide and PCD tools. Trans North Am Manuf Res Inst SME 38: 283-290

57. Brinksmeier E, Janssen R (2002) Drilling of multi-layer composite materials consisting of carbon fiber reinforced plastics (CFRP), titanium and aluminum alloys. CIRP Ann - Manuf Technol 51(1): $87-90$

58. Tashiro T, Fujiwara J, Inada K (2011) Drilling of CFRP/Ti-6Al-4V stacks. Adv Mater Res 325:369-374

59. Shaw MC (2005) Metal cutting principles. Oxford University Press, New York
60. Cotterell M, Byrne G (2008) Dynamics of chip formation during orthogonal cutting of titanium alloy Ti-6Al-4V. CIRP Ann - Manuf Technol 57(1):93-96

61. Liu K, Melkote SN (2006) Material strengthening mechanisms and their contribution to size effect in micro-cutting. J Manuf Sci EngTrans ASME 128(3):730-738

62. Meena A, El Mansori M (2013) Specific cutting force, tool wear and chip morphology characteristics during dry drilling of austempered ductile iron (ADI). Int J Adv Manuf Technol 69(912):2833-2841

63. An Q, Ming W, Cai X, Chen M (2015) Study on the cutting mechanics characteristics of high-strength UD-CFRP laminates based on orthogonal cutting method. Compos Struct 131:374-383

64. Mkaddem A, Ben Soussia A, El Mansori M (2013) Wear resistance of CVD and PVD multilayer coatings when dry cutting fiber reinforced polymers (FRP). Wear 302(1-2):946-954

65. Chen L, El-Wardany T, Harris W (2004) Modelling the effects of flank wear land and chip formation on residual stresses. CIRP Ann - Manuf Technol 53(1):95-98 